$$
321
$$

\title{
ANALYSIS OF ARMF MEASUREMENTS BY ONE-DIMENSIONAL MULTIGROUP DIFFUSION CALCULATIONS
}

D. A. Millsap

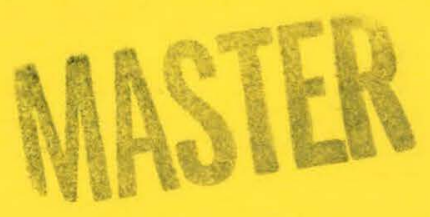

\section{IDAHO NUCLEAR CORPORATION NATIONAL REACTOR TESTING STATION IDAHO FALLS, IDAHO}

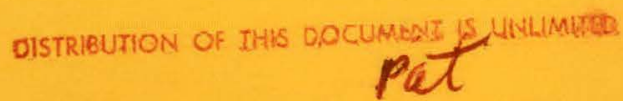

U. S. ATOMIC ENERGY COMMISSION 


\section{DISCLAIMER}

This report was prepared as an account of work sponsored by an agency of the United States Government. Neither the United States Government nor any agency Thereof, nor any of their employees, makes any warranty, express or implied, or assumes any legal liability or responsibility for the accuracy, completeness, or usefulness of any information, apparatus, product, or process disclosed, or represents that its use would not infringe privately owned rights. Reference herein to any specific commercial product, process, or service by trade name, trademark, manufacturer, or otherwise does not necessarily constitute or imply its endorsement, recommendation, or favoring by the United States Government or any agency thereof. The views and opinions of authors expressed herein do not necessarily state or reflect those of the United States Government or any agency thereof. 


\section{DISCLAIMER}

Portions of this document may be illegible in electronic image products. Images are produced from the best available original document. 
Printed in the United States of America Available from

Clearinghouse for Federal Scientific and Technical Information National Bureau of Standards, U. S. Department of Commerce Springfield, Virginia 22151

Price: Printed Copy $\$ 3.00 ;$ Microfiche $\$ 0.65$

\section{LEGAL NOTICE}

This report was prepared as an account of Government sponsored work. Neither the United States, nor the Commission, nor any person acting on behalf of the Commission:

A. Makes any warranty or representation, express or implied, with respect to the accuracy, completeness, or usefulness of the information contained in this report, or that the use of any information, apparatuc, method, or process disclosed in this report may not infringe privately owned rights; or

B. Assumes any liabilities with respect to the use of, or for damages resulting from the use of any information, apparatus, method, or process disclosed in this report.

As used in the above, "person acting on behalf of the Commission" includes any employee or contractor of the Commission, or employee of such contractor, to the extent that such employee or contractor of the Commission, or employee of such contractor prepares, disseminates, or provides access to, any information pursuant to his employment or contract with the Commission, or his employment with such contractor. 


\section{ANALYSIS OF ARMF MEASUREMENTS BY ONE-DIMENSIONAL MULTIGROUP DIFFUSION CALCULATIONS}

\section{LEGAL NOTICE}

(the Unlted Thls report was prepared as an account of Government sponsored work. States, nor the Commission, nor any person ncting on beh or implied, with respect to the accuA. Makes aty warranty or representation, expressed ortiod in thas repoxl, or that tho use racy, completeness, or usefulness of the information contased in this report may not infringe ( of any information, apparatus, method, or process diaclosed in this roport may not hifr inge privately ouned rights; or

B. Assumes any liabillties with respect to the use of, or for damages result

B. Assumes any linformation, apparatus, method, or process diselosed in this report. of any information, apparatus, macting on bebalt of the Commolsaton" includes any emAs used in the commssion, or employee of such contractor, to the extent dat

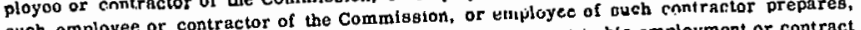
guch employee or contues acteve bu, any infinrmatinn mursuant to his employment or contract

with the Commission, or his employment with such contractor.

\section{IDAHO NUCLEAR CORPORATION}
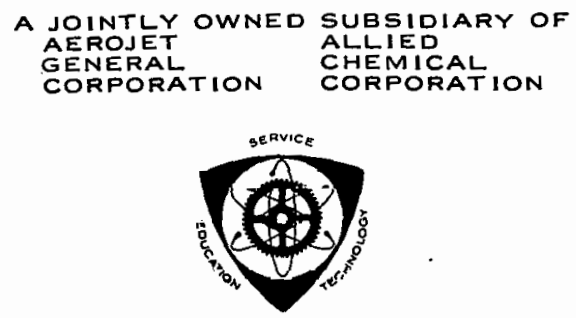

U. S. Atomic Energy Commission Research and Development Report 1s sued Under cimilual AT $(10-1)=1230$ 


\section{ACKINOWLEDGMENTS}

The author wishes to express thanks to A. W. Brown and the members of his Reactor Physics Section for their invaluable assistance in using the various computer codes and in interpreting the calculational results; to $\mathrm{Dr}$. Ed. Fast for extensive help with numerous aspects of the text and its layout; and to Dr. R. G. Fluharty (Branch Manager - Nuclear Technology) and Dr. W. K. Foell (presently on the staff of the Nuclear Engineering Department - University of (Wisconsin) for their encouragement and constructive criticism. 


\section{ABSTRACT}

Reactivity calculations have been made for a selection of materials and compared with results of measurements made on such materials in the ARMF-I and ARMF-II reactors. Except for a representative I/v material, all samples were chosen to have a significant reactivity of scatter relative to that of absorption. The agreement of calculated with measured total reactivities is quite good considering that the calculations employed one-dimensional diffusion theory and an experimentally derived length correction factor. Both 4-group and 18-group reactivity calculations were made; these clearly indicate that more than four groups are required to account properly for the scattering reactions. In addition these comparisons imply that the group structure may also be very important. Of particular significance is the fact that the scattering reactivities are shown to be dominated by reactions occurring in the fission energy range even though the reactors are highly thermalized. The calculations also show that $n, 2 n$ and $n, \alpha$ reactions are detectible, and in the case of beryllium, quite large. Heavy element scattering reactivities are dominated by inelastic reactions. Eighteen group reactivity calculations using perturbed fluxes were compared with calculations using unperturbed fluxes.' The unperturbed fluxes give about the same results except for materials such as water or ${ }^{3}$ He where the thermal flux is highly perturbed by the sample.

The calculations and their comparison to measured values have led to a better understanding of reactivity measurements made in the ARMF, particularly for high energy reactions. The relatively good agreement between calculation and experiment indicate that with a few additional refinements such comparisons may be useful both in checking calculational 
approaches and cross section sets and in accurate predictions of fluxes -in thermal reactors constructed of materials having large scattering cross sections. 
ACKNOWLEDGMENTS ... . . . . . . . . . . . . ii ABSTRACT . . . . . . . . . . . . . . . . . . $\mathrm{i} i \mathrm{C}$

I. INTRODUCTION . . . . . . . . . . . . . . . I

II. EXPERIMENTAL REACTORS AND PROCEDURE'S . . . . . . . . 2

III. CALCULATION OF REACTIVITIES . . . . . . . . . . . 9 IV. DESCRIPTION OF CALCULATIONAL PROCEDURES . . . . . . . . II

V. RESULTS OF CALCULATIONS . . . . . . . . . . . . 21

VI. DISCUSSION . . . . . . . . . . . . 25

VII. SUMMARY AND CONCLUSIONS . . . . . . . . . . 34

VIII. REFERENCES ................ . 56

\section{LIST OF FIGURES}

Fig.

No.

1. Core Loading for ARMF-I . . . . . . . . . . . . 4

¿̇. Calculational Model of ARIMT-I. . . . . . . . . 4

3. Core Loading for ARMF-II . . . . . . . . . . . 6

4. Calculational Model of ARMF-II . . . . . . . . . 6

5. Normalized Real and Adjoint Fluxes, ARMF-I . . . . . 20

6. Normalized Real and Adjoint Fluxes, ARMF-II . . . . . . 20

7. Normalized Absorption Statistical Weight, ARMF-I . . . . 22

8. Normalized Absorption Statistical Weight, ARMF-II . . . . 22

9. Normalized Statistical Weights for Scattering Down, One, Two, and Three Groups, ARMF-I . . . . . . . . . 23

10. Normalized Statistical Weights for Scattering Down, One, Two, and Three Groups, ARMF-II . . . . . . . . . 23 
LIST OF FIGURES (Continued)

Fig.

No.

Nn.

11. Measured vs. Calculated Reactivities, ARMF-I . . . . . 36

12. Measured vs. Calculated Reactivities, ARMF-II . . . . . . 37

LIST OF 'TABLES

Table I - Statistics for Core Representation ARMF-I . . . . 5

Table II - Statistics for Core Representation ARMF-II . . . 7

Table III - Energy and Lethargy Group Structures ........ 13

Table IV - Normalized Unperturbed Real Fluxes, Adjoint Fluxes, and Absorption Statistical Weights, ARMF-I . . . . 18

Table V - Normalized Unperturbed Real Fluxes, Adjoint "Fluxes, and Absorption Statistical Weights, ARMF-II ... . 19

Table VI - Summary of Results, ARMF-I .. . . . . . . . . . 28

Table VII - Summary of Results, ARMF-II . . . . . . . . 29

Table VIII - Group Cross Sections and Reactivities, Water, ARMF-I 38

Table $1 x$ - Group Cross Sections and Reactivities, Heavy Water, AKMH-1 . . . . . . . . ...... . 39

Table X - Group Cross Sections and Reactivities, Beryllium, $\mathrm{ARMF}-\mathrm{I}$. . . ............. 40

Table XI - Group Cross Sections and Reactivities, Carbon, ARMF-I ............... 41

Table XII - Group Cross Sections and "Reactivities, Magnesium,

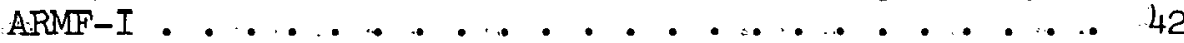

Table XIII - Group Cross Sections and Reactivities, Aluminum, ARMF-I . . . . ........... 43

Table XIV - Group Cross Sections and Reactivities, Zirconium,

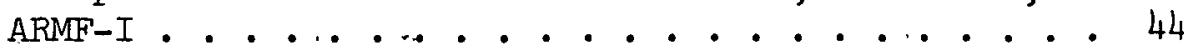

Table XV - Group Cross.Sections and Reactivities, Lead, ARMF-I. 45

Table XVI - Group Cross Sections and Reactivities, Bismuth, ARMF-I . ................ . . 46

Table XVII - Group Cross Sections and Reactivities, Water, ARMF-II .................... 47 


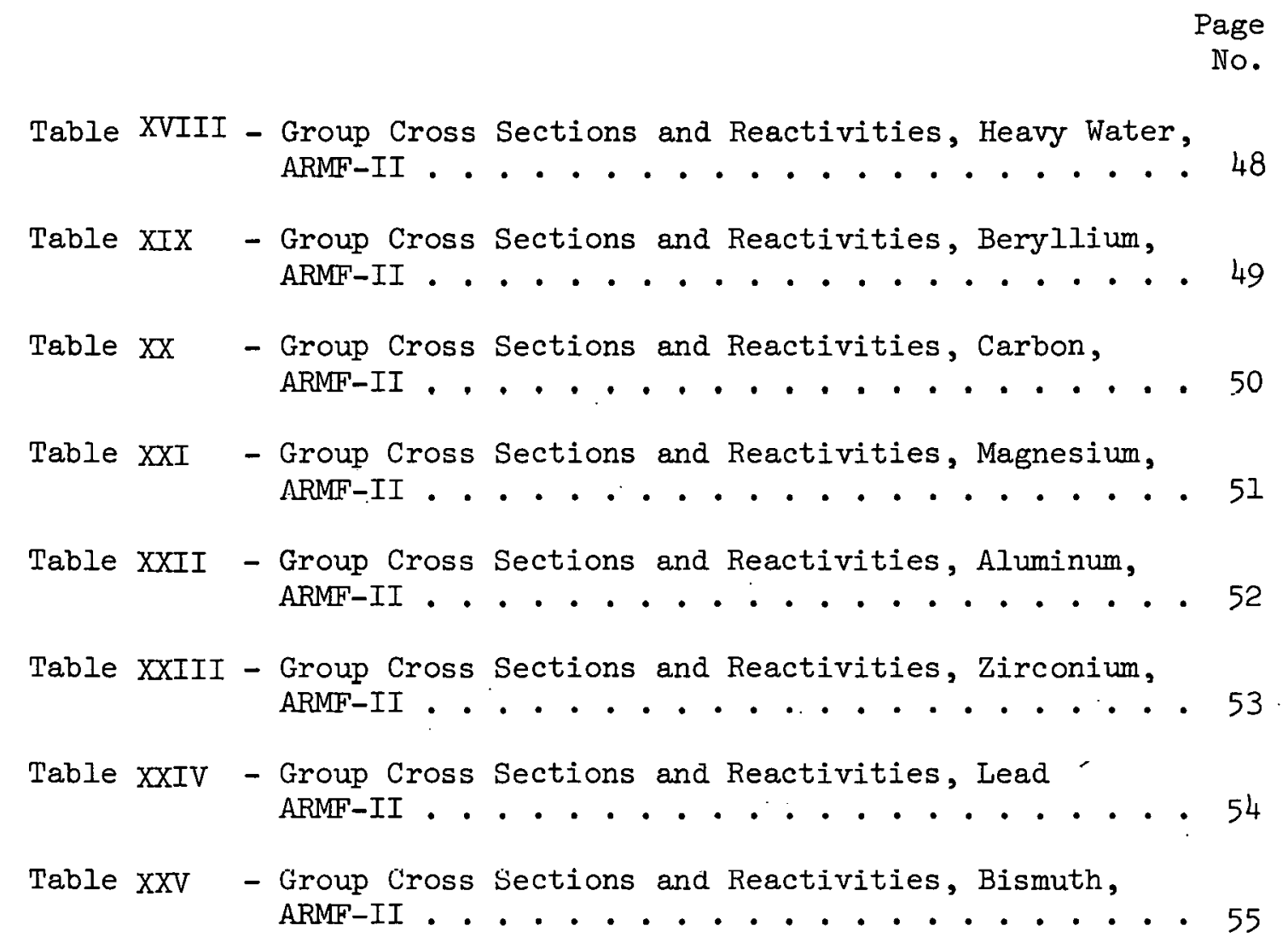




\title{
ANALYSIS OF ARMF MEASUREMENTS BY ONE-DIMENSIONAL MULTIGROUP DIFFUSION CALCULATIONS
}

\author{
D. A. Millsap
}

INTRODUCTION

The ARMF-I and ARMF-II reactors have proven to be valuable for the precision measurement of static reactivities of samples inserted in core positions. The demonstrated usefulness has been primarily for materials having relatively large neutron absorption cross sections in the thermal and/or resonance neutron energy regions. Ordinarily the reactivity measurements on a series of samples of a given material are reduced to an infinite dilution integral cross section or related nuclear parameter. This is accomplished by comparison with the reactivities of standard samples having well known cross sections in the pertinent energy ranges. The interpretation of reactivities has generally been limited to at most three groups; usually a one group absorption model is employed in combination with a calibration for neutron production if fissionable materials are included in the experiment.

$c$

Such few group reactivity analyses are quite satisfactory if the absorption cross sections are large and have a $1 / \sqrt{\mathrm{E}}$ energy dependence or if the statistical weight for absorption is essentially constant over the energy range of interest. Refinements can be made which at least in part compensate for non $I / \sqrt{\mathrm{E}}$ eross sections and neutron temperature effects as well as variations in absorption statistical weights. However, the interpretation will be unsatisfactory if the above conditions are not met to a close degree or if more detailed information is desired. 
The purpose of the multigroup diffusion calculations presented in this report is to explore the usefilness and limitations of typical computer codes when used to calculate reactivities of materials for which experimental results are available. In order to accomplish such calculations, multigroup constants derived from known cross sections are required as input data. The procedure used to calculate reactivities is such that it provides a test of the validity of the combination of computational operations and the set of input cross sections. The study does not yield methnds for the extraotion of infinitely dilute group cross sections from experimentally observed reactivities.

The callculations and measurements to be presented cover only certain aspects of the more general problem. The stuidy considers primarily low absorption scattering samples. Such samples are of interest since it has been found that their reactivity measurements are more difficult to interpret; also. preliminary calculations had indicated that the samples would be sensitive to fast neutron group cross sections. In addition, the initial study has been restricted to one-almensional diffusion theory. The objective has been to explore the problems of reactivity interpretation at thï lievel before going to the considerably more expensive two-dimensional diffusion or transport theory calculations.

\section{EXPERIMENTAL REACTORS AND PROCEDURES}

A brief description will be given here of the Advanced Reactivity Measurement Facilities (ARMF-I and -II) and the normal procedure for making reactivity measurements. It is necessary to have a minimum of 
information in order to understand and evaluate the calculational procedures. More detailed descriptions of the ARMF-I and ARMF-II are given elsewhere $^{(1)}$.

The ARMF reactors are pool type reactors, water moderated, cooled, and reflected, designed for operation at low power and for making precision measurements of small reactivity changes. The core loadings are made as symmetrical as possible. Both reactors have an approximate four-fold rotational symmetry about a vertical axis through the center and four vertical and one horizontal reflection planes. The center region extends vertically through the entire core and is available for placement of the small perturbing samples which are to be measured. The ARMF-I experimental hole is approximately 6.5 inches square, while the ARMF-II has a 1.25 inch square hole. Other experimental measuring positions are primarily the off-center positions in the large central water hole and four 1.25 inch square holes on the diagonals in ARMF-I. The height of the fuel in the core is about $23.5 \mathrm{in.}$ The two core diagrams are given in Figures 1 and 3 with important dimensions and the fuel weights for each element.

The "reactivity" is obtained from the position or orientation of the control elements necessary to keep the reactor just critical. Safety elements are always completely withdrawn from the fueled section of the core during operation. The coarse adjustment is made with the shim which usually remains fixed during a series of measurements. The regulating rod is a 2.5 inch diameter cylinder, with a full length of cadmium covering 126 degrees of the outside surface. The rod is located just outside the fuel core. Regulation is accomplished by rotating this rod about its vertical axis to change the proximity of the cadmium to 


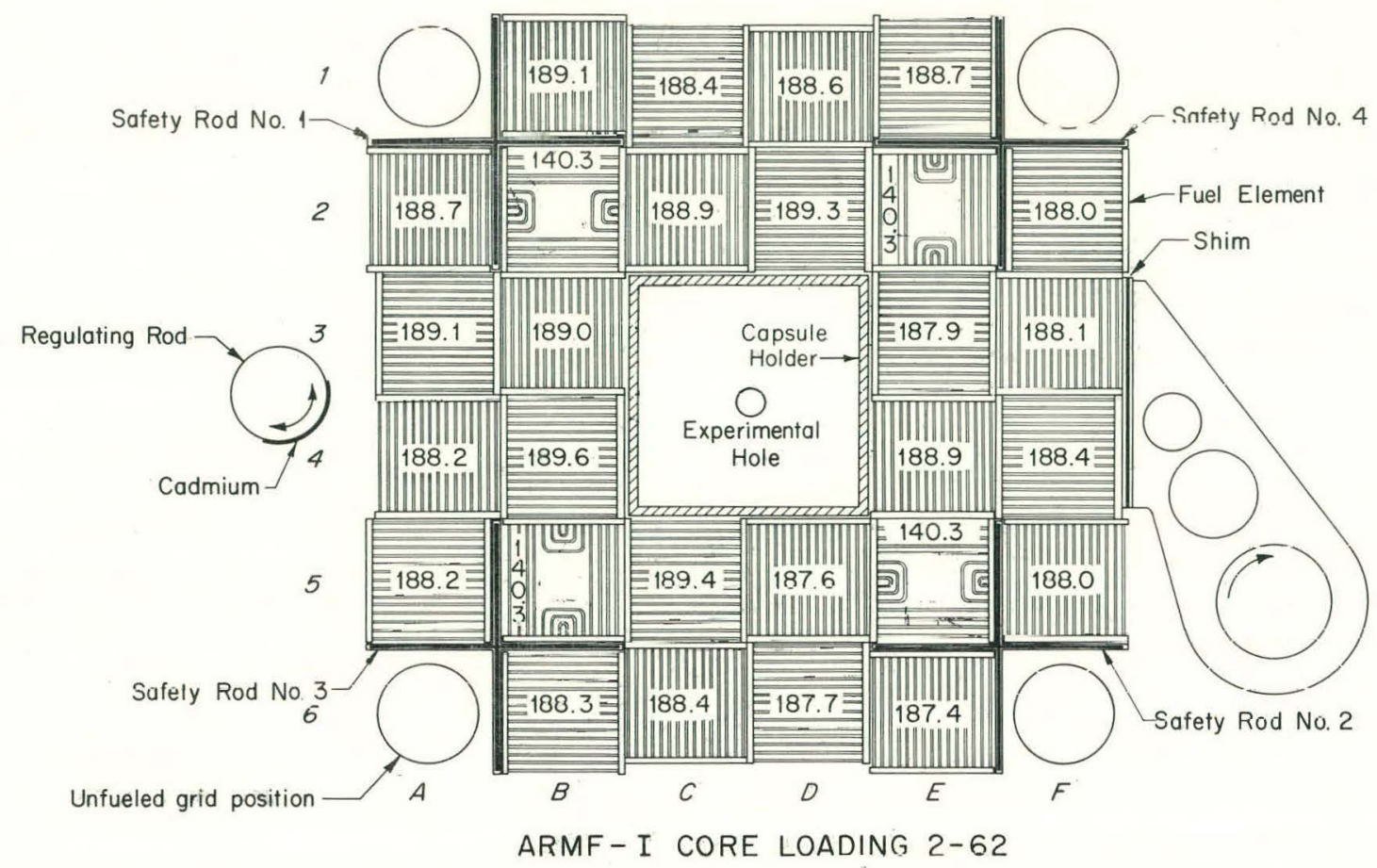

NOTE Numbers on elements are grams of $U^{235}$.

Total 5085.1 g U ${ }^{235}$. Figure 1 - Core Loading for ARMF-I

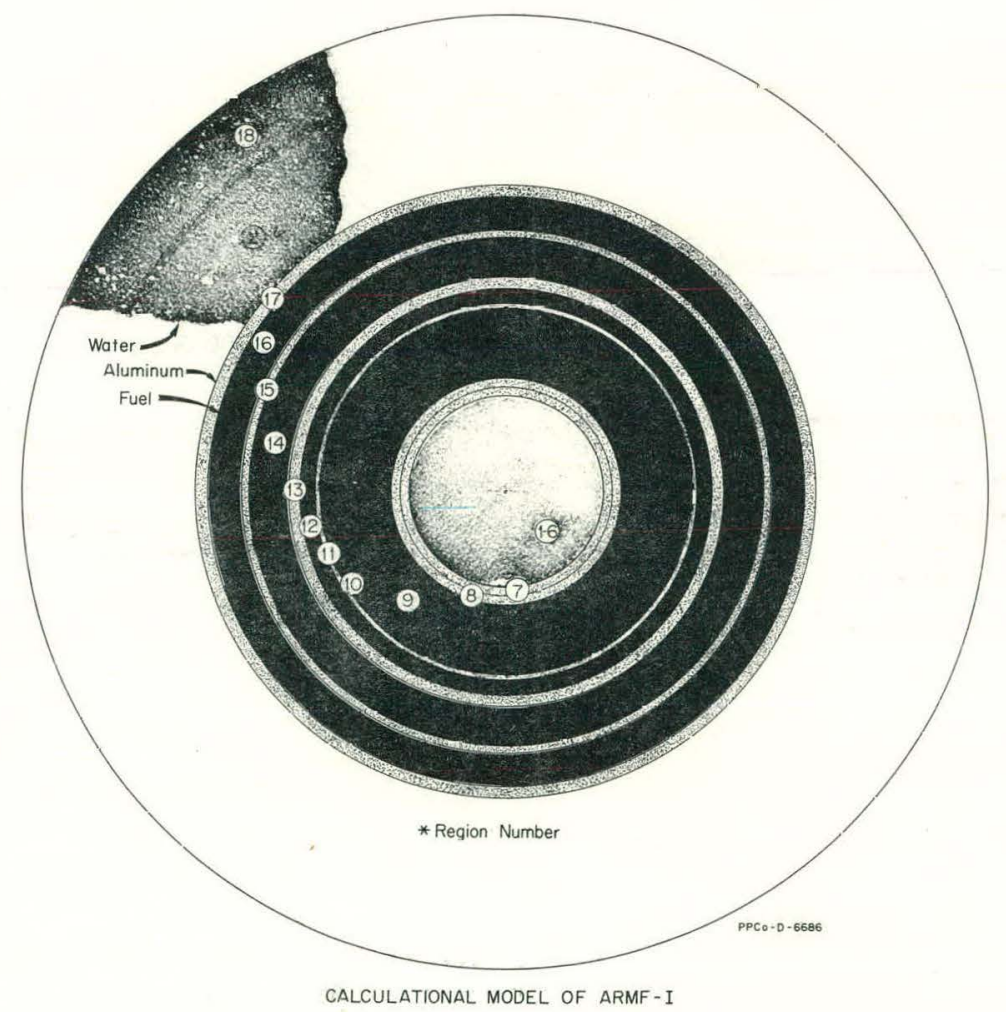

Figure 2 - Calculational Model of ARMF-I 
$\underline{\text { TABLE I }}$

STATISTICS FOR CORE REPRESENTATION

ARMF-I

\begin{tabular}{|c|c|c|c|}
\hline & Material in Region Number & $\begin{array}{c}\text { Outer Radius } \\
\text { of Region } \\
(\mathrm{cm}) \\
\end{array}$ & $\begin{array}{l}\text { Number of } \\
\text { Mesh Points } \\
\text { in Region } \\
\end{array}$ \\
\hline 1 & Sample or Void & 1.1049 & 10 \\
\hline 2 & Marlex Capsule & 1.3272 & 2 \\
\hline 3 & Aluminum Can & 1.5684 & 2 \\
\hline 4 & Water & 3.9213 & 4 \\
\hline 5 & Water & 6.2741 & 4 \\
\hline 6 & Water & 8.6269 & 4 \\
\hline 7 & Capsule Holder & 9.4036 & 2 \\
\hline 8 & Fuel Element Side Plates & 10.2175 & 2 \\
\hline 9 & Standard Fuel Elements & 16.1233 & 14 \\
\hline 10 & Special Fuel Elements (Curved Plate Section) & 16.6234 & 4 \\
\hline 11 & Water Annulus (in Special Fuel Elements) & 16.9440 & 8 \\
\hline 12 & Special Fuel Elements (Straight Plate & & \\
\hline & $\begin{array}{r}\text { Section) } \\
\text { Section }\end{array}$ & 18.3778 & 4 \\
\hline 13 & Fuel Element Side Plates & 19.3650 & 2 \\
\hline 14 & Standard Fuel Elements & 23.0341 & 10 \\
\hline 15 & Control Rod Followers & 23.6227 & 2 \\
\hline 16 & St.andard Filel Filement.s & 26.7132 & 8 \\
\hline 17 & Fuel Element Side Plates & 27.1088 & 2 \\
\hline 18 & Water Reflector & 43.1088 & 16 \\
\hline
\end{tabular}


NOTE: Numbers on elements are grams of $\mathrm{U}^{235}$.

Total $2654.9 \mathrm{~g} \mathrm{U}^{235}$.

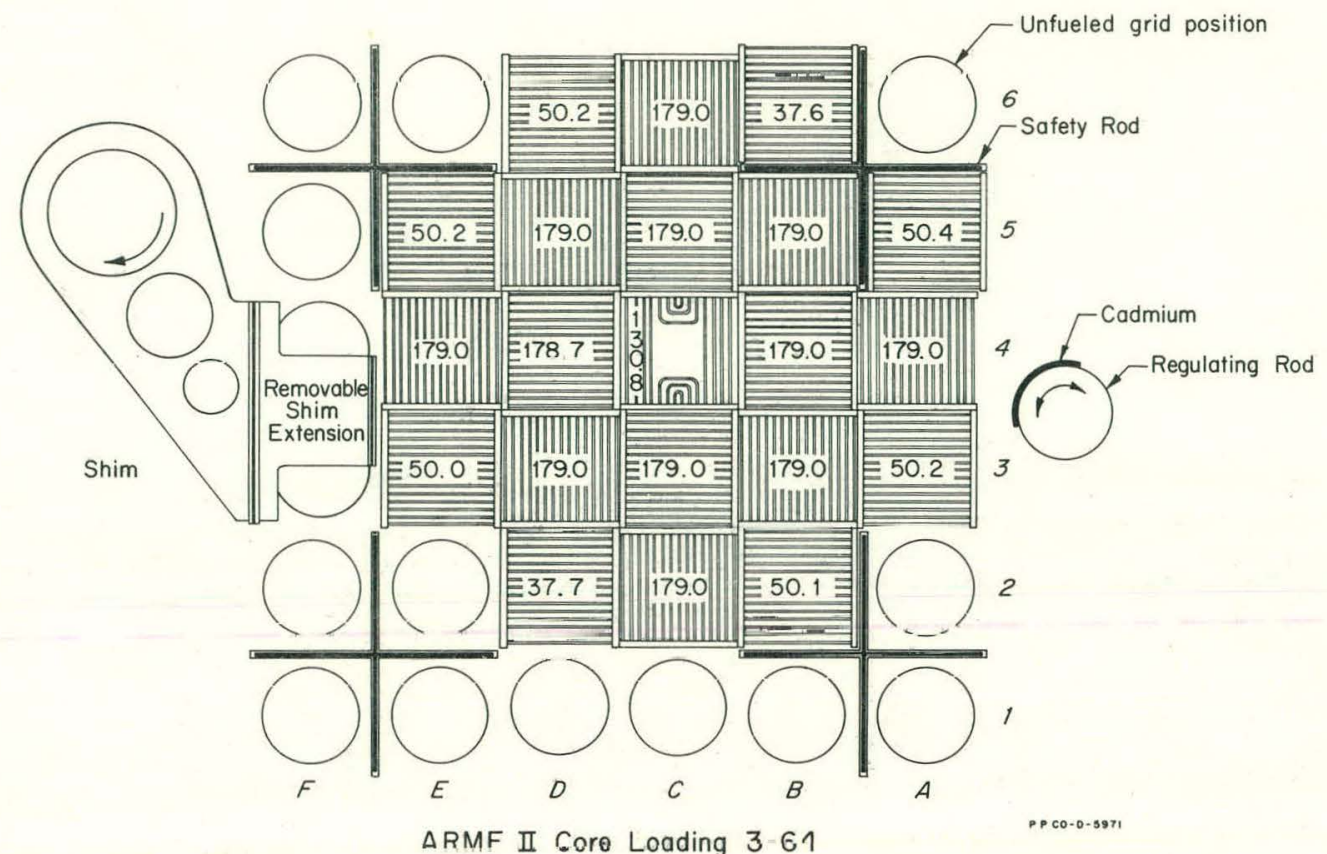

Figure 3 - Core Loading for ARMF-II

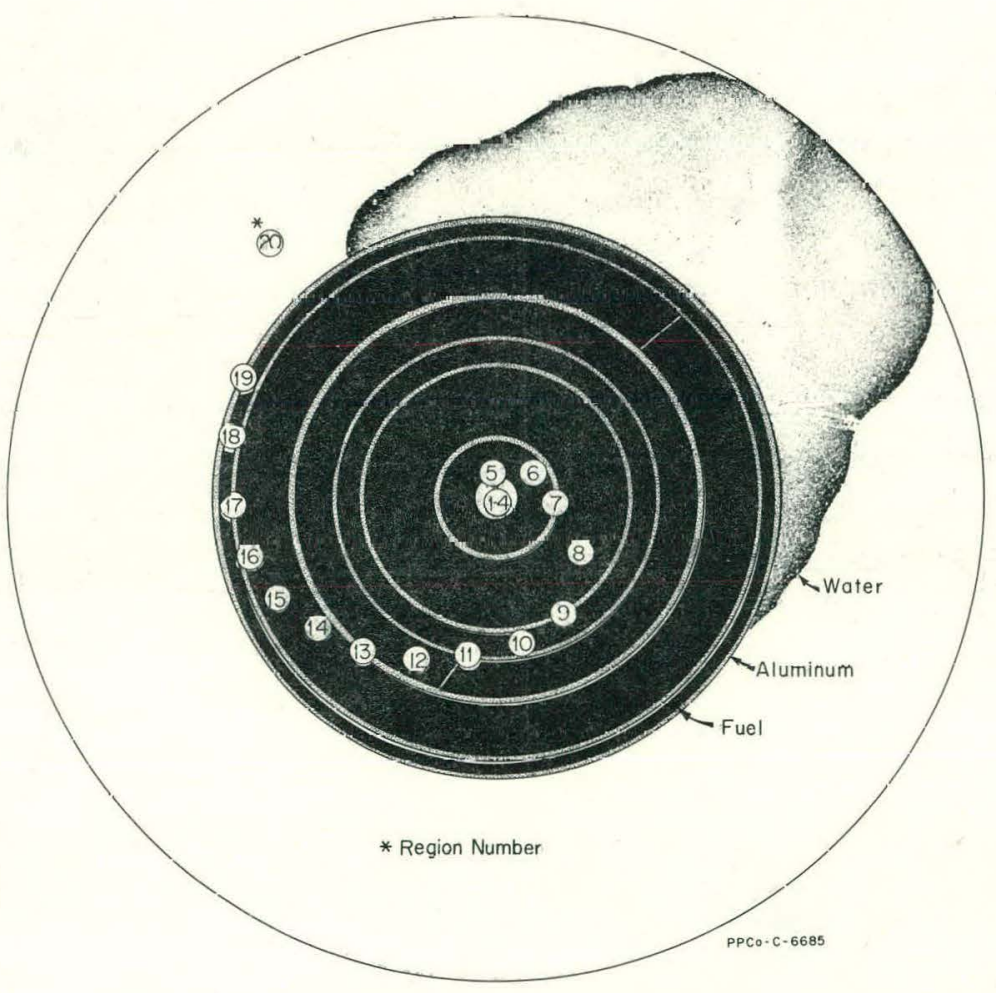

CALCULATIONAL MODEL OF ARMF-II

Figure 4 - Calculational Model of ARMF-II 
TABLE II

STATISTICS FOR CORE REPRESENTATION

ARMF-II

\begin{tabular}{|c|c|c|c|}
\hline & Material in Region Number & $\begin{array}{l}\text { Outer Radius } \\
\text { of Region } \\
\text { ( } \mathrm{cm} \text { ) }\end{array}$ & $\begin{array}{l}\text { Number of } \\
\text { Mesh Poi,nts } \\
\text { in Region } \\
\end{array}$ \\
\hline 1 & Sample or Vold & 1.1049 & 10 \\
\hline 2 & Marlex Capsule & 1.3272 & 2 \\
\hline 3 & Aluminum Can & 1.5684 & 2 \\
\hline 4 & Water & 1.6401 & 2 \\
\hline 5 & Special Fuel Elements (Curved Plate Section) & 2.6047 & 4 \\
\hline 6 & Special Fuel Elements (Straight Plate Section) & 1) 4.4097 & 6 \\
\hline 7 & Fuel Element Side Plates & 4.9770 & 2 \\
\hline 8 & Staridard Fuel Elements & 10.1267 & 14 \\
\hline 9 & Fuel Element Side Plates & 10.6394 & 2 \\
\hline 10 & Standard Fuel Elements & 12.3324 & 6 \\
\hline 11 & Fuel Element Side Plates & 12.7567 & 2 \\
\hline 12 & Standard Fuel Elements & 15.5086 & 8 \\
\hline 13 & Fuel Elcment Side Plates & 16.0151 & 2 \\
\hline 14 & Loose Leaf Fuel - $50 \mathrm{gm}$ Elements & 18.2830 & 6 \\
\hline 15 & Standard Fuel Elements & 19.3173 & 4 \\
\hline 16 & Loose Leaf Fuel - $50 \mathrm{gm}$ Elements & 20.2990 & 4 \\
\hline 17 & Cuntrul Rod Followers & 20.6345 & $\hat{\varepsilon}$ \\
\hline 18 & Loose Leaf Fuel - $38 \mathrm{gm}$ Elements & 21.5563 & 4 \\
\hline 19 & Fuel Element Side Plates & 21.8627 & 2 \\
\hline 20 & Water Reflector & 37.8627 & 16 \\
\hline
\end{tabular}


the fuel. The regulating rod under servo control "hunts" continuously to find the critical point. A rod position reading is the instantaneous orientation of the rod about its vertical axis. The measurement consists of the average of a large number of such instantaneous position readings of regulating rod orientation taken at a uniform rate of 16 per second. The position is translated into relative reactivity $\Delta \mathrm{k} / \mathrm{k}$, by a previously determined relationship between the two, i.e. the calibration procedure.

The sequence of data taken in a sample meacurement is as follows: A measurement is taken of the unperturbed reactor, then one or more samples followed by another unperturbed reactor measurement. The net value of the sample is the difference between the reactivity norresponding to the sample measurement and that of the unperturbed reactor. Bracketing the sample measurement on both sides with unperturbed reactor measurements allows, a degree of correction (by linear time interpolation) if there is a drift in this "zero" rcading.

The calibration of the regulating rod consists of determining the shape of the curve relating the regulating rod position to reactivity, and then scaling this curve to read in absolute reactivity units. A small sample is measured a large number of times.in various regions of the regulating rod span so as to cover the complete range. The assumption is made that the reactivity value of the sample remains constant. The results are fitted by either a power series or a trigonometric series expansion (2). Scaling is done by setting the regulating rod a precisely measured span from a critical position and measuring the reactor period that results. This period is related to the reactivity by the inhour equation ${ }^{(3)}$. The assumptions made here will be discussed later in more detail. 
Data from the reactors are processed by the DUZIT calculation code ${ }^{(4)}$. The data as given by the reactor read-out system are recorded on IBM punch cards. A calibration data card is added to give the analytical expression of the calibration curve. Results then give the net reactivities of the sample with respect to the unperturbed reactor and/or to some arbitrary "standard" sample.

\section{CALCULATION OF REACTIVITIES}

Putnam has shown ${ }^{(5)}$ that the reactivity due to a perturbation may be expressed either as a function of eigenvalues alone or as one of two alternate expressions involving real and adjoint fluxes along with appropriate cross sections.

The expression using eigenvalues is simply

$$
\rho(t)=\left[\lambda(t)-\lambda_{c}\right] \lambda_{c}^{m} \lambda^{n}(t) / \lambda_{c} \lambda(t)
$$

where

$$
\begin{aligned}
\rho(t)= & \text { the calculated reactivity effect of the perturbed condition } \\
& \text { relative to some critical (i.e., "unperturbed") state of the } \\
& \text { reactor } \\
\lambda_{c}= & \text { the calculated eigenvalue (or correction factor) for some } \\
& \text { critical state of the reactor } \\
\lambda(t)= & \text { the calculated eigenvalue for the perturbed condition. } \\
m, n= & \text { arbitrary exponents. }
\end{aligned}
$$

For the present work any time dependency can be ignored; henceforth we shall abbreviate $\lambda(t)$ to $\lambda$ and $\rho(t)$ to $\rho$. Thus, from any conventional multigroup reactor code the reactivity, $\rho$, corresponding to a perturbed condition can be calculated from the eigenvalues $\lambda$ and $\lambda_{c}$. The real fluxes, even livugh calculaled, are nut requirea. Obviously', the 
eigenvalue differences method will give only the gross reactivity of. an assumed perturbed condition.

For this report it was desired to examine calculated reactivities in more detail. When the reactivities of individual scattering, absorption, or $n, 2 n$ reactions are available the accuracy of the calculational model may be assessed and individual cross section entries for given multigroup reactions may be evaluated, at least to a degree. A common procedure applicable for this purpose is to calculate the real and adjoint fluxes corresponding to a reference or unperturbed case. By using suitable relations based on perturbation theory these fluxes are then combined with appropriate cross sections to obtain the reactivity of a perturbing sample. [See, e.g.., Davey ${ }^{(6)}$.]. From such a perturbation calculation the contribution to the total reactivity of individual: reactions may be obtained as a matter of course. Although eigenvelue: calculations for all but, the reference case are avoided and. considerable computer time: thus saved, the method" is, of course, less rigorous, than the eigenvalue differences approach: This will lead to significant errors for'highly perturbing samples.

One can retain the rigor, of the eigenvalue differences: method. within the formalism of a perturbation calculation by use of one of . the two alternate expressions for reactivity derived by. Putnam: These equally rigorous alternate methods require calculations of one of the two following types: (1) the real fluxes obtained from an eigenvalue calculation for a perturbed case are combined with the adjoint fluxes from a reference or unperturbed case along. with the cross section perturbations; (2.) the adjoint fluxes obtained. from the eigenvalue calculation for the perturbed case are combined. with the real fluxes: of the 
reference (unperturbed) case with appropriate cross sections. By following one of these alternate procedures one can obtain the individual contributions to the total reactivity and retain the rigor of the eigenvalue differences method. However, it is necessary to make an eigenvalue calculation for each case in order to obtain the perturbed real or adjoint fluxes as required by the chosen alternative.

\section{DESCRIPTION OF CALCULATIONAL PROCEDURES}

The flux and reactivity calculations presented in this report are obtained from multigroup cylindrical representations of the ARMF-I and ARMF-II cores. The treatment has been limited to the diffusion approximation. Diagrams of the cores as calculated are given in Figures 2 and 4. The ARMF-I core was represented by 18 regions, the ARMF-II by 20 regions. Both representations used 101 space points. The various annuli represent reactor features such as sample location, sample holders, side plates, fuel plates, control rod followers, and reflector; they were chosen to be identical to the midplane areas of these features of the actual reactors. Additional information for the core representations are given in Tables $I$ and II.

The computer code, AIM-6 ${ }^{(7)}$, has been used for the core calculations. AIM-6 is a multigroup, one dimensional diffusion code which handles up to 18 energy groups, 20 regions, 101 space points, and allows downscattering to a given group from any higher group for macroscopic crosssection entries. In addition to an eigenvalue, it calculates real and adjoint fluxes, and provides for a punched-card output of these results. Two series of calculations were made for the various samples; a preliminary one using a 4-group energy structure and another using an 
18-group structure. Group energy and lethargy spacing for the two structures are given in Table III. Epithermal cross sections for the 4-group core calculations were obtained by use of the computer code GAM-1 ${ }^{(8)}$; for the 18-group core calculations the PHROG computer code was used. PHROG (Phillips-Hanford Revision of GAM-1) incorporates a variety of program and library changes to the basic GAM-1 program. However, in order to insure that comparison of sample reactivities between the 4- and 18 -group calculations were on a reasonably consistent basis, the GAM-1 cross section library : was used to obtain all sample epithermal cross sections. All thermal cross sections were calculated using TEMPEST-II ${ }^{(9)}$. Since the thermal energy range for the 4- and 18-group calculations was the same, identical thermal cross sections were used for both such calculations for the respective cores. Sample cross sections for the ARMF-I calculations were obtained by averaging over the spectra given by GAM-I and TEMPEST-II for a water environment. For ARMF-II the spectra used was that of a homogenized Mark-c fuel element of the type used in that reactor.

A set of nine samples from the ARMF neutron scattering experiment $(10)$ was chosen for a comparison of measured and calculated reactivities. The set consists of $\mathrm{H}_{2} \mathrm{O}, \mathrm{D}_{2} \mathrm{O}, \mathrm{Be}, \mathrm{C}, \mathrm{Mg}, \mathrm{Al}, \mathrm{Zr}$, Ph and Ri. A limited comparison was also made for a sample containing 0.213 atmospheres of ${ }^{3} \mathrm{He}$ gas. The sample holders were polyethylene capsules inside aluminum cans. The samples were measured in the central measuring positions of both reactors. The reference or unperturbed condition for the above samples was an empty sample holder.

Reactivities for the sample were calculated primarily by PERT, a computer code based on diffusion-perturbation theory ${ }^{(11)}$. The PERT 


\section{FOUR GROUP MODEL}

\begin{tabular}{cccc}
$\begin{array}{c}\text { Group } \\
\text { Number }\end{array}$ & $\begin{array}{c}\text { Upper Limit } \\
\text { Energy } \\
(\mathrm{ev})\end{array}$ & $\begin{array}{c}\text { Lower Limit } \\
\text { Lethargy }\end{array}$ & $\begin{array}{c}\text { Group Width } \\
\text { Lethargy }\end{array}$ \\
\cline { 2 - 3 } 1 & $10.0 \times 10^{6}$ & 0.0 & 2.5 \\
2 & $8.21 \times 10^{5}$ & 2.5 & 5.0 \\
3 & $5.53 \times 10^{3}$ & 7.5 & 9.25 \\
4 & 0.532 & 16.75 & $\infty$
\end{tabular}

EIGHTEEN GROUP MODEL

Group

Number

1
2
3
4
5

6

7

8

9

10

11

$1 ?$

13

14

15

16

17

18
Upper Limit

$$
\text { Energy }
$$

$\frac{(\mathrm{ev})}{10.0 \times 10^{6}}$

$3.68 \times 10^{6}$

$1.35 \times 10_{5}^{6}$

$4.98 \times .10_{5}^{5}$

$1.83 \times 10^{5}$

$6.74 \times 10_{4}^{4}$

$2.48 \times 10_{3}^{4}$

$9.12 \times 10^{3}$

3. $36 \times 10^{3}$

$1.23 \times 10^{3}$

454.00

167.00

61.40

22.60

8.32

3.06

1.125

0.532
Lower Limit

Lethargy

0.0

1

2

3
4

5 I

61

7

81

9

10

11

12

13

14

15

16

16.75
Group Width

Lethargy

1

1

1

1

1

1

1

1

1

1

1

0.75 
code uses the card output containing the real and adjoint fluxes as calculated by AIM-6. From the calculated real and adjoint fluxes and the appropriate perturbing cross sections the original code reads out in addition to the total reactivity change, the reactivity contributions due to fission, absorption, scattering, and radial leakage, if such occur. Axial leakage is taken into account only if the $\mathrm{DB}^{2}$ terms are included. wi.th the absorption cross-section entries. This original code was modified to calculate the reactivity contribution of the $n, 2 n$ reaction as well. Also, the modified version prints out the individual contributions of the above reactions for each cross-section entry. Some' reactivity effects were ignored in the calculations. None of: the ten samples have a fission cross section, so: this effect. was not examined. The effect of radial leakage was found to be negligible in. all cases, presumably because of the low flux gradients which existed in the samples. It was recognized that the effect of axi a.1 1eakage. from the samples could not. be duplicated by the one-dimensional approximation since this would imply that the sample (for calculation purposes) would be the same length as the core. Such a sample representation would considerably overestimate the true leakage, particularly for the void calculation. To avoid this, the axial leakage for all calculations was equalized by placing the axial buckling: equal to zero. in the sample and sample holder regions. Thus, any possible reactivity effect due to axial leakage, i.e., a $\mathrm{DB}_{z}{ }^{2}$ term, was ignored in the eigenvalue: calculations. 
Therefore, the only reactivity effects calculated for the sample considered were those due to absorption, scattering and $n, 2 n$ reactions. In PERT these effects are represented as

$$
\begin{gathered}
\Delta \rho_{a}=-\sum_{i=1}^{n}\left(\phi_{i} \phi_{i}^{*}\right) \delta \Sigma_{a_{i}} / I \\
\Delta \rho_{s}=\sum_{i=1}^{n-1} \sum_{j=i+1}^{n} \phi_{i}\left(\phi_{j}^{*}-\phi_{i}^{*}\right) \delta \Sigma_{s_{i \rightarrow j}} / I \\
\Delta \rho_{n, 2 n}=\sum_{i=1} \sum_{j=i} \phi_{i}\left(2 \phi_{j}^{*}-\phi_{i}^{*}\right) \delta \Sigma_{n, 2 n_{i \rightarrow j} / I}
\end{gathered}
$$

where

$$
I=\sum_{r=1}^{n} \sum_{k=1}^{n}\left\{\Phi_{i}^{r}\left(\nu \Sigma_{f}\right)_{i}^{r} x_{k} \Phi_{k}^{* r}\right\}
$$

and

$$
\begin{aligned}
& \sum_{k=1}^{n} x_{k}=1 . \\
& \Delta \rho=\text { the partial reactivity indicated by the subscript } \\
& \phi_{i}=\text { the volume integrated real flux in the sample region } \\
& \Phi_{i}^{r}=\text { the volume integrated real flux in region } r \text {, group } i \\
& \phi_{i}^{*}=\text { the volume integrated adjoint flux in the sample region } \\
& \Phi_{i}^{*}=\text { (the volume integrated adjoint flux in region } r \text {, group } k \\
& \delta \Sigma=\text { perturbation in the cross section for the reaction and } \\
& \text { (the central region) for group } i
\end{aligned}
$$




$$
\begin{aligned}
& \left(\nu \Sigma_{f}\right)_{i}^{r}=\text { number of neutrons per fission times the fission cross } \\
& \text { section for region } r \text {, group } i \\
& x_{k}=\text { fraction of the total fissions produced with energies } \\
& I=\text { a normalizing factor - this particular choice of the } \\
& \text { normalizing factor, I, used by PERT yields a reactivity } \\
& \text { which corresponds identically to the reactivity as given } \\
& \text { by eigenvalue differences if } m=n=0 \text { in equation ( } 1 \text { ) } \\
& \text { a, } s, n-2 n=\text { absorption, scattering, } n, 2 n \\
& \dot{i}, j, \mathrm{k}:=\text { group indices } \\
& n=\text { number of groups in the calculation } \\
& r=\text { number of regions in the calculation }
\end{aligned}
$$

The actual procedure used in calculating the sample reactivities was as follows: (1) an AIM-6 calculation was made for the reference case to obtain the unperturbed real and adjoint fluxes in addition to the eigenvalue, i.e., $\lambda_{e}$; (2) AIM-6 calculations were then made for each sample to obtain their perturbed real fluxes. along with the corresponding $\lambda^{\prime} s$; (3) the perturbed real fluxes were combined in turn with the unperturbed adjoint fluxes and the appropriate perturbing cross sections to obtain the reactivity of each sample; (4) the eigenvalue differences method was then employed as a check on the total reactivities so calculated; (5) a reactivity calculation was also made using the same perturbing cross sections in combination with the unperturbed real and adjoint fluxes of the reference case; (6) all results were scaled to take into account the actual length of the sample. 
Item (5) is a straight perturbation calculation. Comparison of such results with those of (3) and (4) should reveal substantial differences only if the real fluxes are significantly perturbed by the various samples.

Since a one-dimensional calculation necessarily implies that the sample is the same length as the core it is essential to employ a length correction factor which scales the calculated reactivity to take into account the actual length of the measured samples. The length correction factor (L,C.F.) used in this report was based on an empirical relation obtained by Rogers ${ }^{(12)}$ in his study of water displacement coefficients in the ARMF-I. 'The relation is

$\rho(h)=2.826+\left(2.533 \times 10^{-2}\right) h-\left(7.622 \times 10^{-3}\right) h^{2}+\left(1.331 \times 10^{-4}\right) h^{3}$

and gives the reactivity worth per unit volume of sample at a height, $h$, above the reactor centerline. The sample used to get the experimental data was a two-inch long solid cylinder of aluminum, one-half inch in diameter. From this a length correction factor was defined as

$$
\text { L.C.F. }=\frac{-\int_{h_{1}}^{0} \rho(h) d h+\int_{0}^{h} \rho(h) d h}{110.2}
$$

where $h_{1}$ and $h_{2}$ are the lengths of the sample below and above the reactor centerline, respectively. This assumes axial symmetry. The denominator is the reactivity per unit area of an actual sample which extended through the responsive length of the core axis. $\Lambda$ careful examination of sample holder positioning plates show that the sample materials in position give values for $h_{1}$ and $h_{2}$ of $4.84 \mathrm{~cm}$ and $7.30 \mathrm{~cm}$ (total sample length $12.14 \mathrm{~cm}$ ). For these values of $h_{1}$ and $h_{\hat{G}}$ a value 


\section{TABLE IV}

NORMALIZED UNPERTURBED REAL FLUXES, ADJOINT FLUXES, AND ABSORPTION STATISTICAL WEIGHTS

ARMF-I

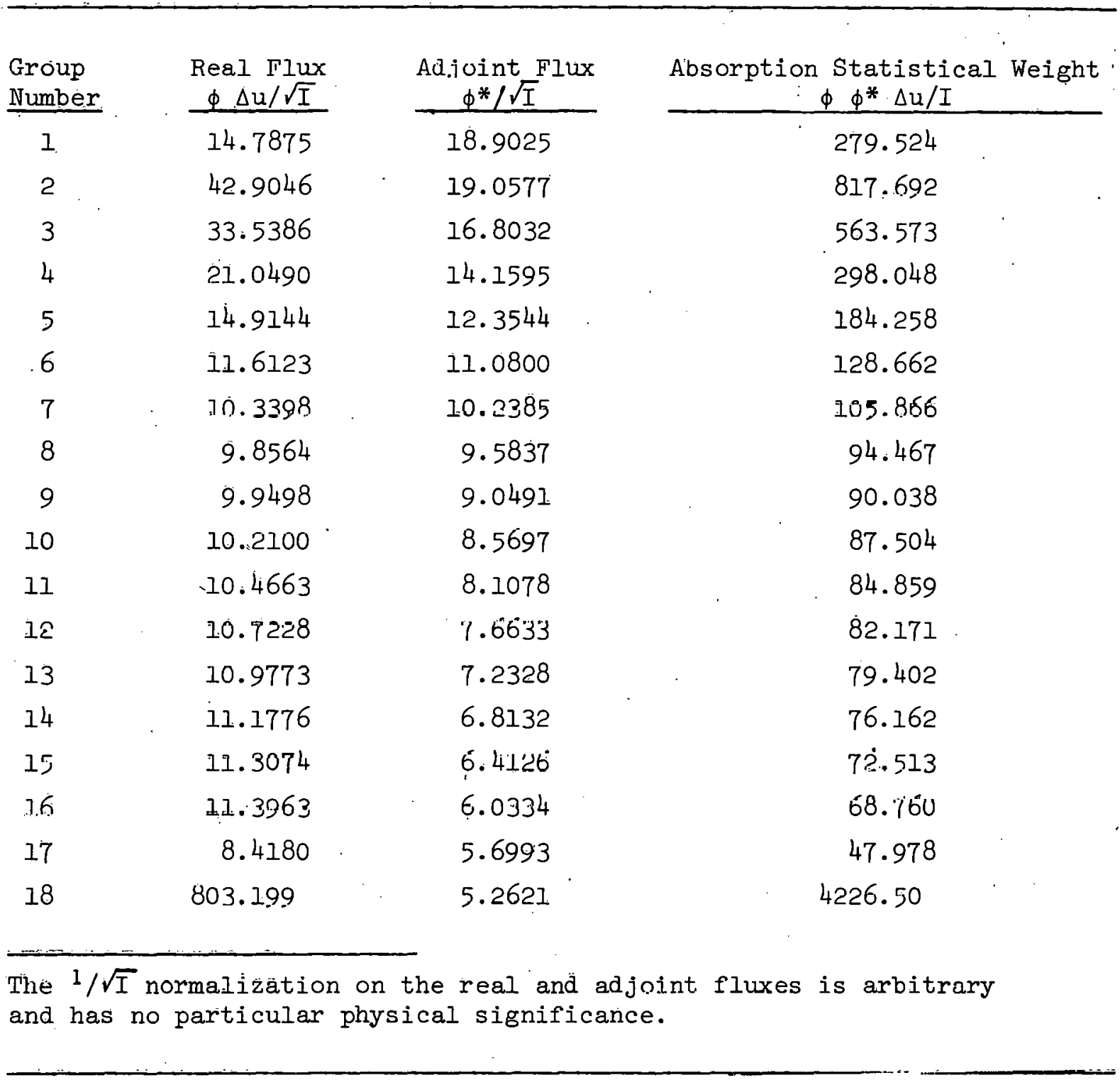


TABLE V

NORMALIZED UNPERTURBED REAL FLUXES, ADJOINT FLUXES, AND ABSORPTION STATTSTICAL WEIGHTS

ARMF-II

\begin{tabular}{|c|c|c|c|}
\hline $\begin{array}{l}\text { Group } \\
\text { Number }\end{array}$ & $\begin{array}{l}\text { Real Flux } \\
\phi \Delta 12 / \sqrt{I} \\
\end{array}$ & $\begin{array}{l}\text { Adjoint Flux } \\
\phi^{*} / \sqrt{I}\end{array}$ & $\begin{array}{c}\text { Absorption Statistical Weight } \\
\phi \phi^{*} \Delta \mathrm{u} / \mathrm{I}\end{array}$ \\
\hline 1 & 59.2854 & 29.0138 & 1720.09 \\
\hline 2 & 226.044 & 36.2082 & 8184.58 \\
\hline 3. & 195.782 & 42.6644 & 8352.90 \\
\hline 4 & 116.691 & 46.7472 & 5455.07 \\
\hline 5 & 76.0624 & 48.8224 & 3713.39 \\
\hline 6 & 57.3133 & 49.9247 & 2861.41 \\
\hline 7 & 49.0194 & 50.6613 & 2483.26 \\
\hline 8 & 45.0089 & 51.3200 & 2309.86 \\
\hline 9 & 43.8665 & 51.8552 & 2274.78 \\
\hline 10 & 43.4079 & 52.3480 & 2272.38 \\
\hline 11 & 42.8990 & 52.8237 & 2266.13 \\
\hline 12 & 42.3116 & 53.2758 & 2254.09 \\
\hline 13 & 41.6022 & 53.7012 & 2234.08 \\
\hline 14 & 40.5667 & & 2102.98 \\
\hline 15 & 39.6163 & 54.5127 & 2159.50 \\
\hline 16 & 38.6692 & 55.0394 & 2128.29 \\
\hline 17 & 27.7064 & 55.4318 & 1535.76 \\
\hline 18 & 543.444 & 55.3636 & 30087.0 \\
\hline
\end{tabular}



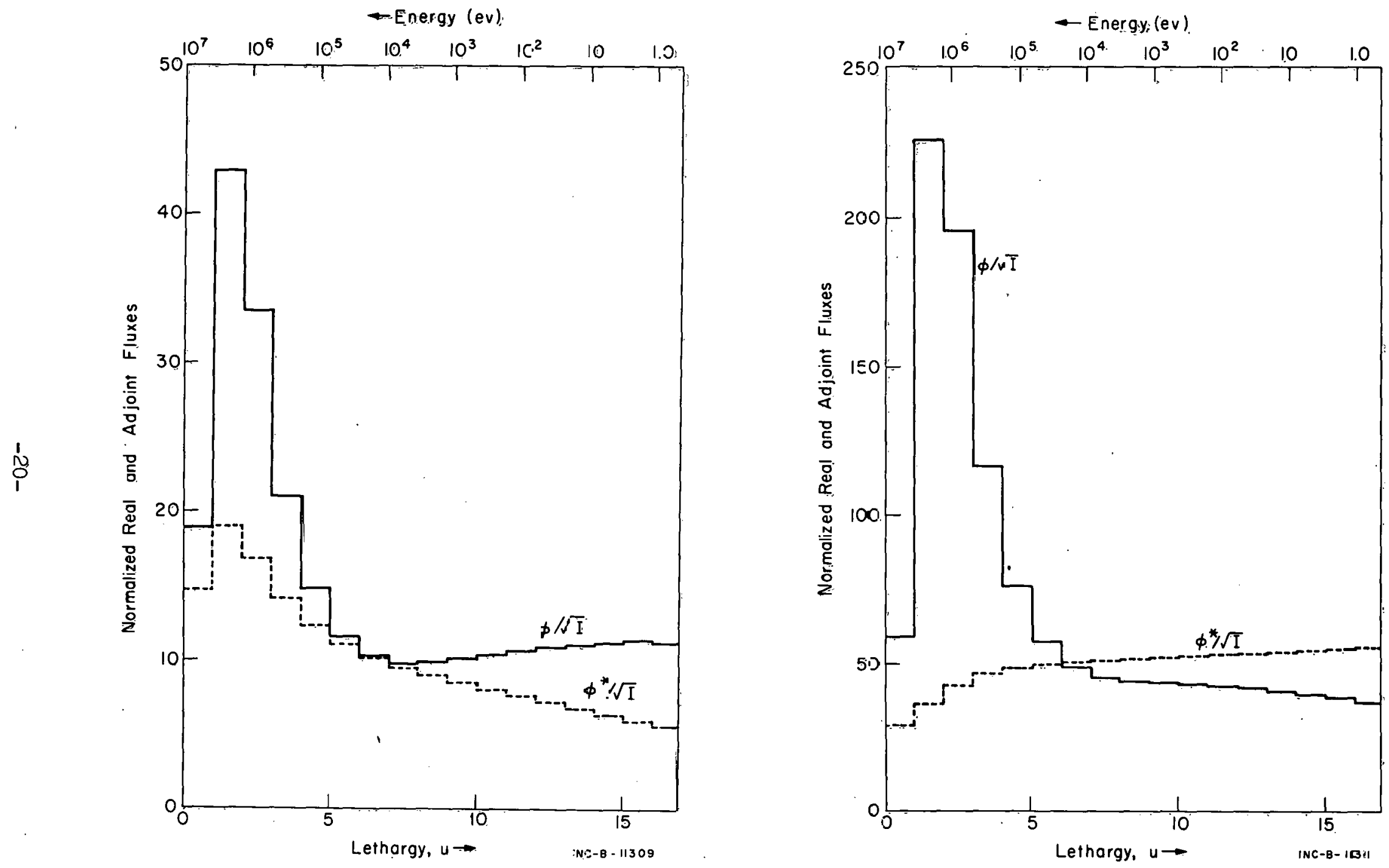

Figure 5 - Normalized Real and Acjoint Fluxes, ARMF-I. Figure 6 - Normalized Real and Adjoint Fluxes, ARMF-II. 
of L.C.F. $=0.3097$ was obtained. All calculated reactivity values given in this report have been scaled by this factor. It was assumed that the same L.C.F. applied to both reactors even though the empirical relation found by Rogers was obtained from the ARMF-I.

An alternate method of obtaining a length correction factor assumes that vertical real and adjoint flux profiles follow a cosine distribution curve. The L.C.F. so obtained is 0.3172 (for an assumed effective reactor height of $74.93 \mathrm{~cm}$ ) indicating good agreement with the empirically derived value.

\section{RESULTS OF CALCULATIONS}

The results presented fall into two categories: (1) calculated real and adjoint fluxes and statistical weights, and (2) calculated reactivities for the various samples compared with their experimental value.

Tables IV and V give the calculated real and adjoint fluxes along with their products for the ARMF-I and ARMF-II reactors for the 18-group energy structure. The quantities given are for the unperturbed (empty capsule) case only. They have been normalized so that their product gives $\phi_{i} \phi_{i}^{*} / I$ which when multiplied by a macroscopic cross section for absorption, $\delta \Sigma_{a_{i}}$, will give the absolute value of the reactivity (in $\mu \mathrm{k}$ ) for absorption in the $i-$ th group. Thus the $\phi_{i} \phi_{i}^{*} / I$ have the units $\mu \mathrm{k} \mathrm{cm}$. These products are the statistical weights for absorption. Graphs related to the quantities given in Tables IV and V are plotted in Figures 5 through 8. For the graphs, the values of real flux shown in the tables have been divided by the appropriate lethargy widths to give the average real flux applicable to each group. Both the rea $\perp$ and 

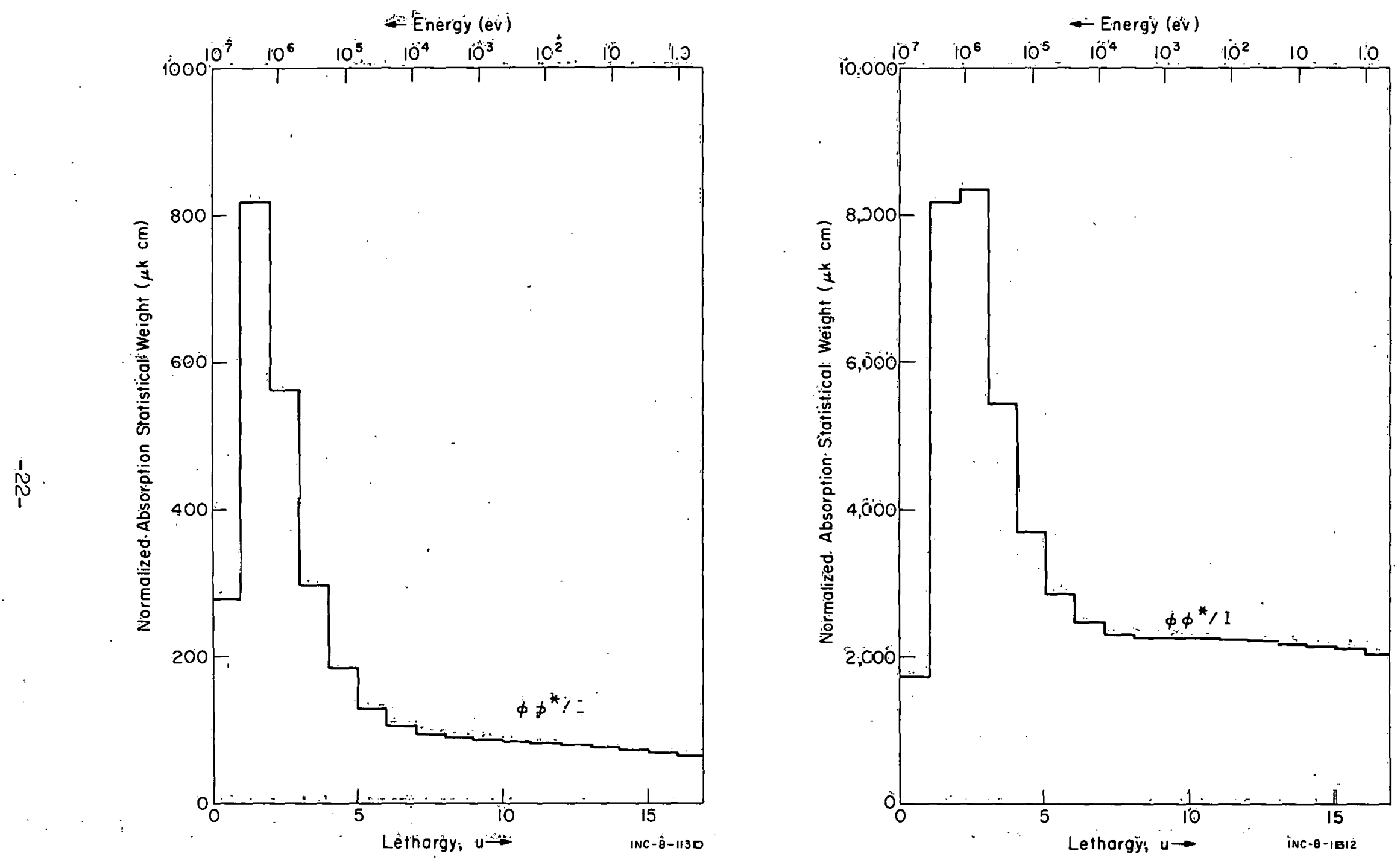

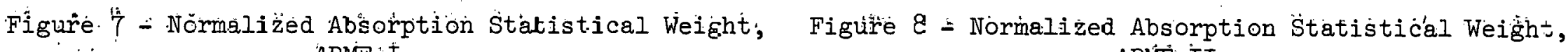
ARMF-1. ARMF-II 


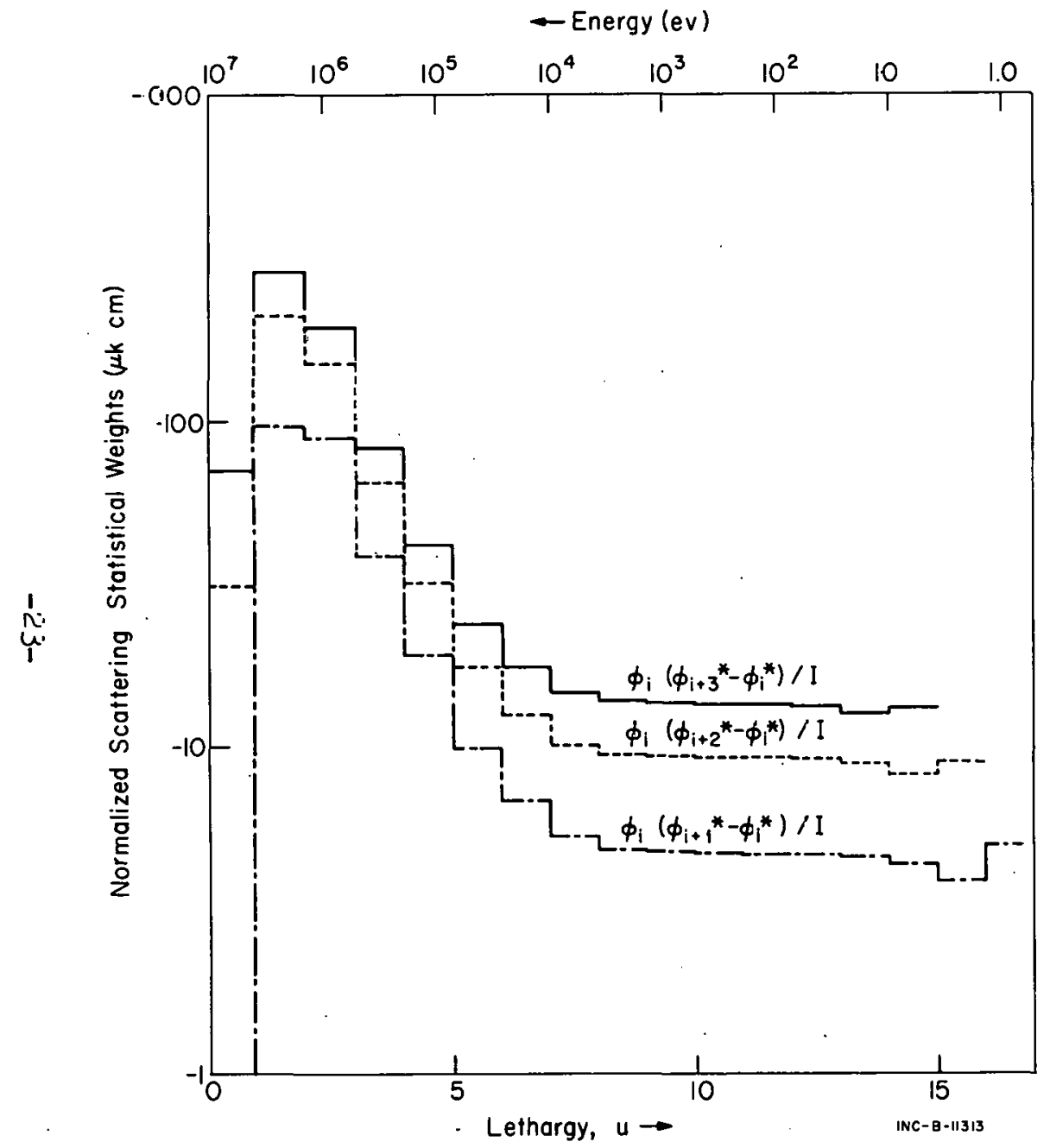

Figure 9 - Normalized Statistical Weight Scattering Down One, Two, and Three Groups, AFMF-I.

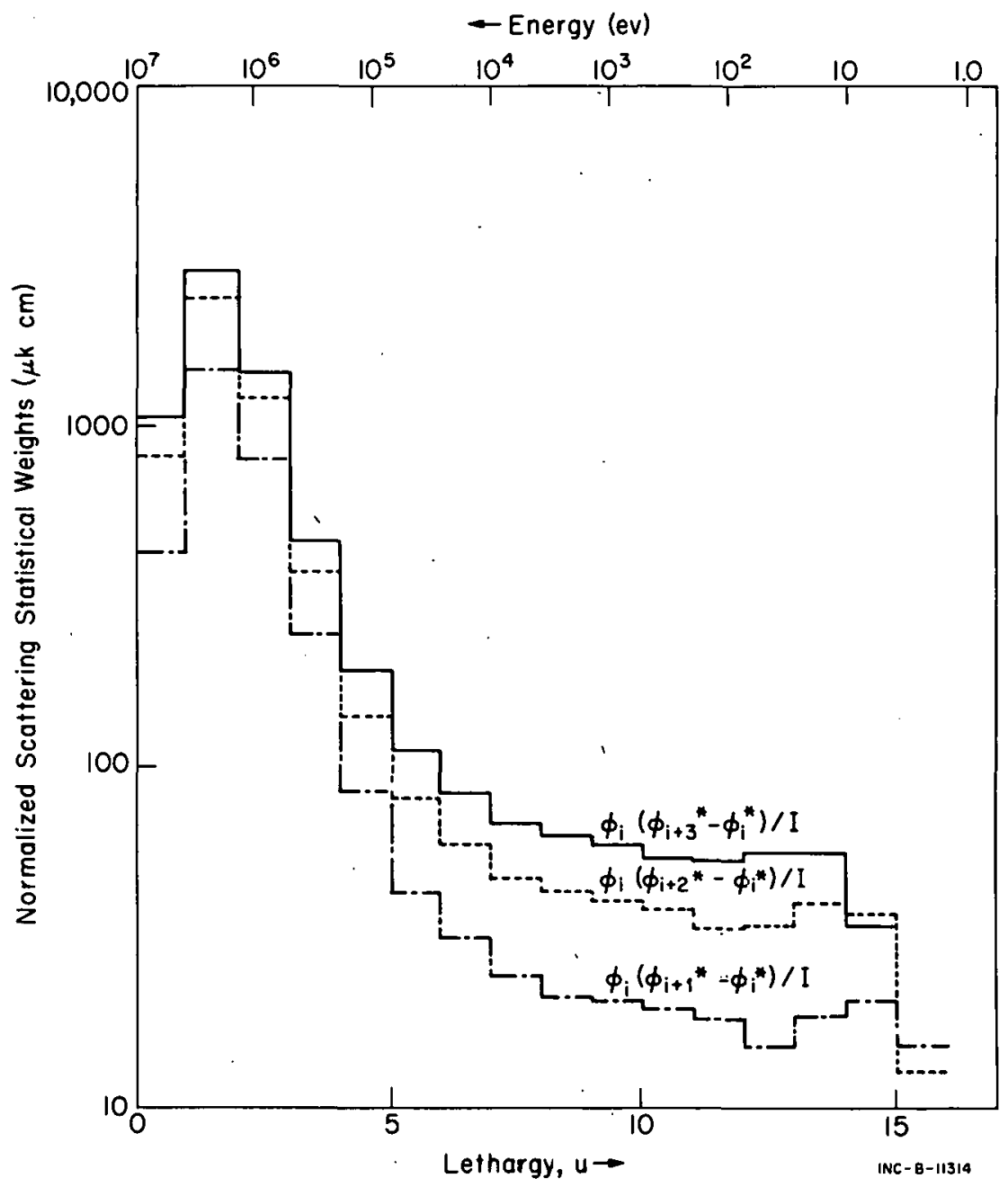

Figure 10 - Normalized Statistical Weights for Scattering Down, One, Two, and Three Groups, ARMF-II. 
adjoint fluxes have been divided by $\sqrt{\mathrm{I}}$, a completely arbitrary scale. factor used to give these vaiues what is. considered to be an appropriate magnitude. The thermal fluxes values are not shown on the graphs since: no lethargy width can be assigned to the thermal group.

Figures 9 and 10 are plots of the quantities $\phi_{i}\left(\phi_{j}^{*}-\phi_{i}^{*}\right) / I$ for the ARMF-I and ARMF-II. These will be referred to as the statistical weights for scattering from group $i$ to group $j$. The three bar graphs give the calculated energy dependent statistical weights for scattering down one, two and three groups, respectively. Tt, shmind be noted that cross sections for scattering down more than about three groups are generally negligible for this choice of group structures.

Tables VI and VII summarize the resultis nf the reactivity measurements and of the calculations for both energy structures for ARMF-I and ARMF-II, respectively. In both tables, columns 4 and 5 give the results of the PERT calculations obtained using perturbed fluxes and column 6 usirg unperturbed fluxes. Calculations using unperturbed fluxes were not made for the 4-group moiel, Since the cigenvalue differences gave reactivities which in nearly all cases compared to within $0.2 \%$ of the total reactivities given in columns 4 and 5 (Tables VI andivII), these results: are not given separately. The reactivities are for the samples described, previously. Four-group calculations. were not made for ${ }^{3} \mathrm{He}$. 'l'ables VIII through XXV present a detailed compilation of the calculated reactivities for the scattering samplcs in the two.reactors. Given. in the tables are the individual cross-section entries as calculated by GAM-I and TEMPEST-II, and the corresponding reactivity contributed by the entry. Total: reactivities contributed by absorption, 
scattering, and $\mathrm{n}$, 2n reactions are also shown. The overall calculated totals are compared with experimental values. The detailed compilation has been made for the perturbed flux calculation exclusively.

\section{DISCUSSION}

The real and adjoint fluxes for the 18-group calcatiations reveal many: of the features important to an understanding of the reactivity response of the. ARMF-I and ARMF-II reactors. Not surprisingly, the thermal flux is by far the dominant flux in both reactors and givesrise to proportionately high statistical weights for thermal absorption. The epithermal real flux is comparatively flat over a significant energy range and can be considered essentially $\mathrm{l} / \mathrm{E}$ from group 8 .through 17 $(3360 \mathrm{eV}$ to $0.532 \mathrm{eV})$ in. both reactors. The slopes of the adjoint fluxes in this range are such that the resulting statistical weights for absorption are fairly constant, particularly in ARMF-II. Both reactors show high. statistical weights for absorption through the high energy range ( $9120 \mathrm{eV}$ to $10 \mathrm{MeV})$. Since absorption cross sections at high energies are much lower than thermal cross sections for the great majority of: materials, the reactivity due to high energy absorption will usually: be insïgnificant. Thus, for a $1 / \mathrm{v}$ absorber, such as $3_{\text {He, the }}$ therma absorption reactivity is more than $96 \%$ of the total reactivity even in ARMF-II; fast absorption contributes essentially nothing to the total reactivity. However, for a few of the very low absorbers, such as those considered in this report, a threshold $n, \alpha$ reaction may actually contribute more to a material's rcactivity than the thermal $\mathrm{n}, \gamma$ reaction (e..g., beryli:ium): 
The slope of the adjoint flux through a given energy range determines whether the scatter reactivity will be positive or negative in that range. In ARMF-I the scatter statistical weights (see Figures 9 and 10), though low, are all negative except for scattering from group 1 to group 2 (not shown on the semilog plot of Figure 9). In ARMF-II the scatter statistical weights are much higher and are all positive except for scattering from group 17 to 18 (not shown in Figure 10). In both reactors the slopes of the adjoint fluxes are greatest through the energy range where the fast flux is peaking (approximately groups 1 to 6) giving very high statistical weights for scattering relative to those at lower energies (approximately groups 7 to 18 ). In fact, the stititistical weight for ccattcring from groups 2 to 3 in ARMF-II is so high that if the cross-section entry $\delta \Sigma_{s_{2 \rightarrow 3}}$, for water was as high as the asymptotic value attained in the I/E range, the calculated reactivity for the water sample would be increased by over $600 \mu \mathrm{k}$ from this reaction alone. Becauce of thcse high statistical weights, scatter reactions in the fission range dominate the total scatter reactivity for all materials considered in the report.

With a few exceptions, the calculated reactivities obtained using the perturbed fluxes do not differ greatly from those using unperturbed fluxes. In the ARMF-I the greatest difference occurs in the results for ${ }^{3} \mathrm{He}$; the reactivity calculated using perturbed fluxes is $11 \%$ lower than that calculated using unperturbed fluxes. The other materials give differences of less than $6 \%$. In ARMF-II the perturbed flux calculation differs markedly from that of the unperturbed flux calculation for water. The calculated scatter reactivity is reduced 
by about $32 \mu \mathrm{k}(3.4 \%)$ while the magnitude of the thermal absorption. reactivity is increased by nearly $1.52 \mu \mathrm{k}(29.5 \%)$. The result is a substantial improvement in the agreement between calculated and measured reactivities. The other materials show only minor changes in calculated reactivities resulting from the substitution of perturbed for unperturbed fluxes, with the exception of ${ }^{3}$ He (magnitude of reactivity down $6 \%$ ). It would appear that the major effect of using perturbed fluxes in the reactivity calculation is to give a better estimate of the thermal absorption reactivity.

The calculated perturbed flux reactivities given in Tables VI through XXV show fair agreement with measured results. The 18-group perturbed flux calculations exhibit a significant improvement over the 4-group calculations, particularly in ARMF-II. The differences between the two sets can best be studied by referring to columns 4 and 5 of Tables VI and VII. In ARMF-I there is a consistent lowering of the magnitude of the thermal absorption reactivity by 1 or $2 \%$ while the scatter reactivity shows a small increase for all materials except water. The net effect is a slight improvement in the agreement between measured and calculated reactivities in going from 4 to 18 groups. :Heavy water a'lone shows substantial improvement. In ARMF-II the change from 4 to 18 :groups gives a marked improvement for all materials for which both cases were calculated (4-group calculations were not made for $3_{\mathrm{He}}$ ). The magnitude of the thermal absorption reactivity is increased by nearly $5 \%$ while the scatter reactivity is increased by an average of over $+29 \mu \mathrm{k}$. Clearly, the number of groups and the choice of group structure is highly important for reactivity calculations in the ARMF-II. 
TABLE VI

SUMMARY OF RESULTS

ARMF - I

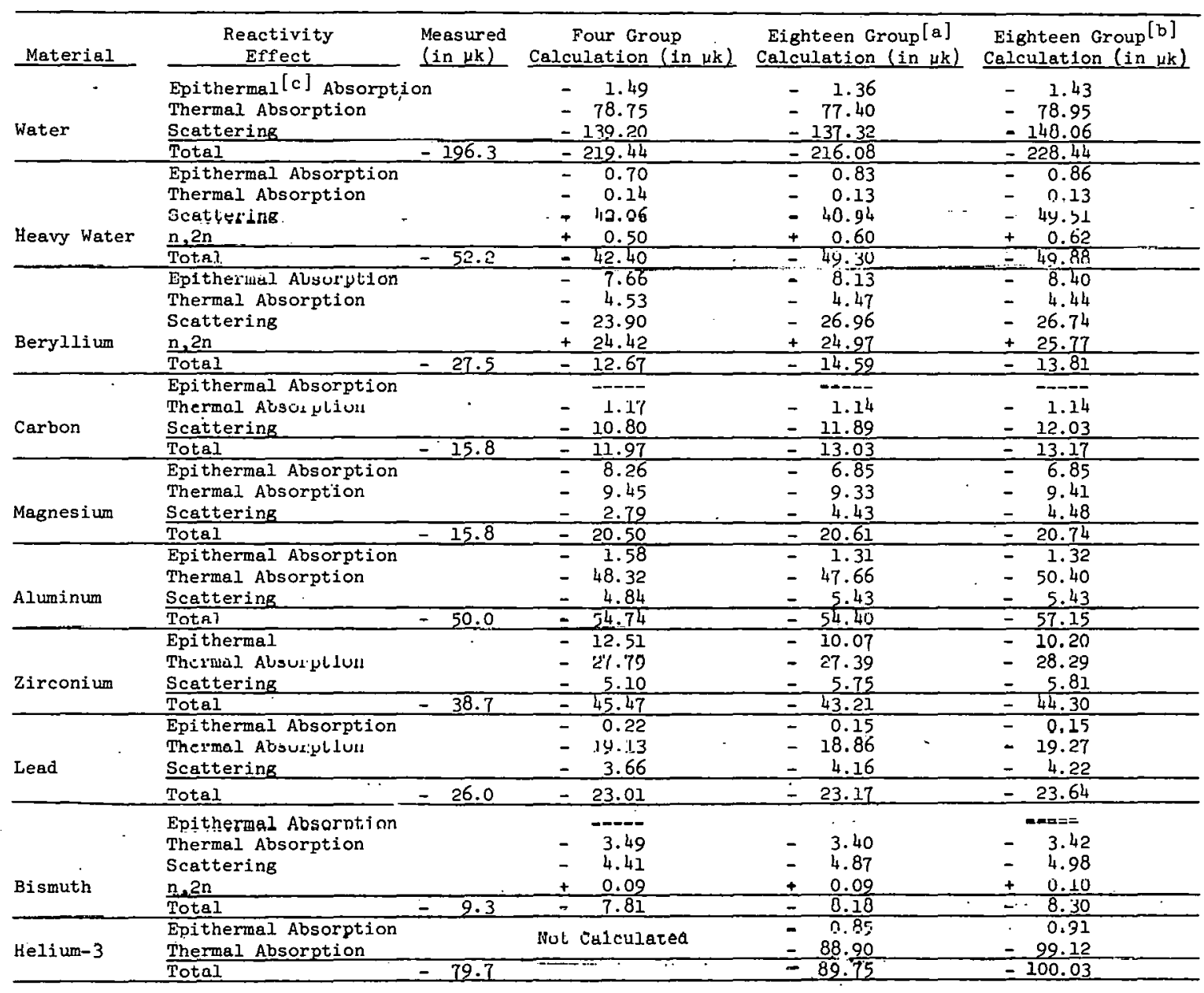

[a] Using perturbed real fluxes, unperturbed adjoint fluxes.

[b] Using unperturbed real fluxes, unperturbed adjoint fluxes.

[c] Epithermal $\equiv 10 \mathrm{MeV}$ to $0.532 \mathrm{eV}$. 


\section{TABLE VII}

SUMMARY OF RESULTS

ARMF-II

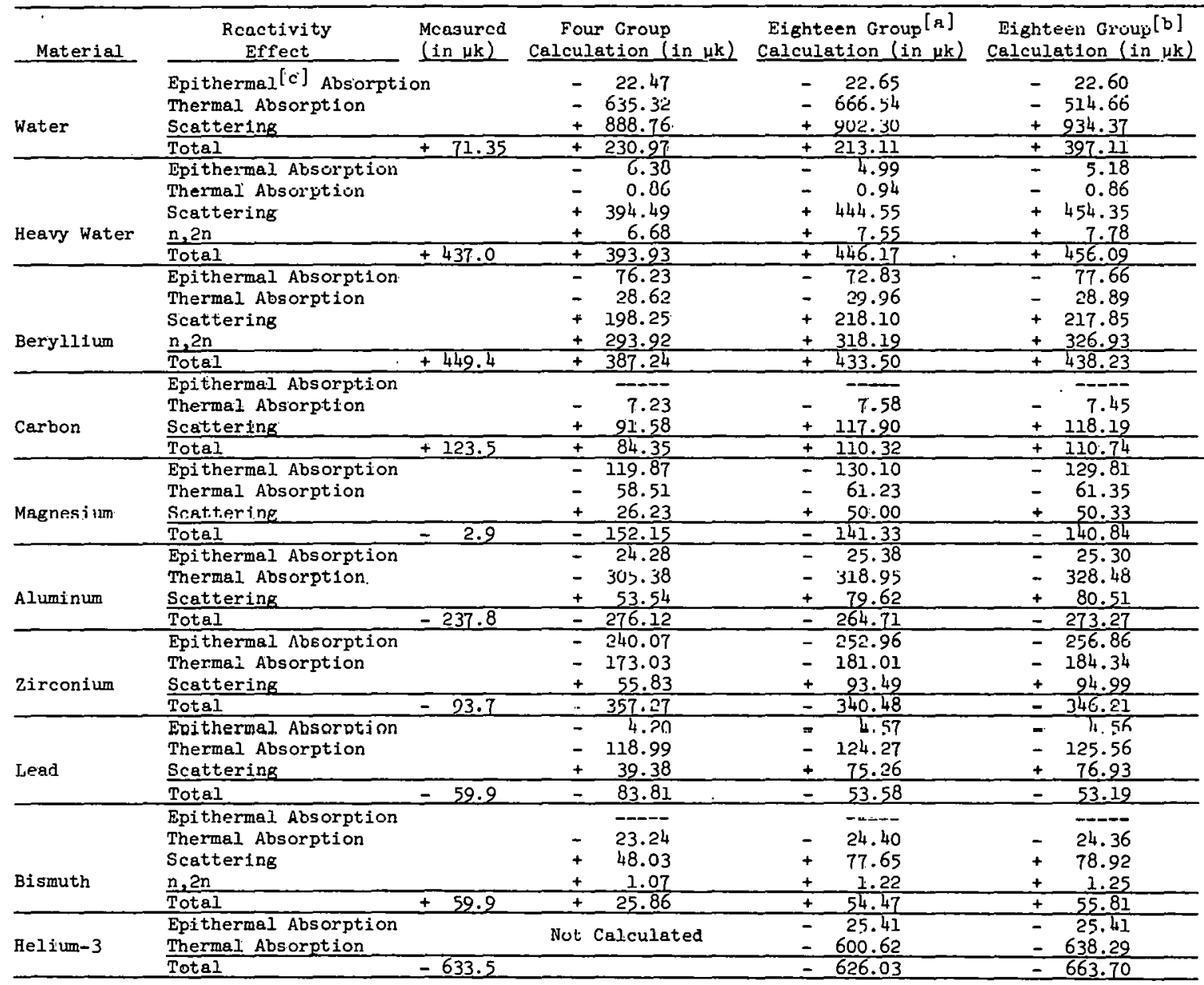

[a] Using perturbed real fluxes, unperturbed adjoint fluxes.

[b] Using unperturbed real fluxes, unperturbed adjoint fluxes.

[c] Epithermal $\equiv 10 \mathrm{MeV}$ to $0.532 \mathrm{eV}$. 
The error of a calculated net reactivity could be defined relative to the measured value, i.e.,

$$
\text { relative difference } \equiv \varepsilon=\frac{\Delta \rho_{c}-\Delta \rho_{m}}{\Delta \rho_{m}}
$$

where c and m signify "calculated" and "measured", respectively. However, since both positive and negative components may be present, such a definition may yield unrealistic values, particularly when $\Delta 0_{\text {III }} \sim 0$. An example nf this is magnesium in $\Lambda$ RMF-II which appeur's to have absorption and scatter reactivities nearly equal in magnitudc.

A relative difference would be better defined as

$$
\varepsilon=\frac{\sum_{i}\left|\Delta \rho_{c_{i}}-\Delta \rho_{m_{i}}\right|}{\sum_{i}\left|\Delta \rho_{m_{i}}\right|}
$$

where the subscript i refers to the reactivity components due to absorption, scattering, etc. However, experimental results for the quantities, $\Delta \rho_{m_{1}}$, are not available and are not easily obtainable when the individual reactivity effects are not all of the same sign.

For present purposes the following expression is a reasonable compromise:

$$
\varepsilon=\frac{\Delta \rho_{c}-\Delta \rho_{m}}{\sum\left|\Delta \rho_{c_{i}}\right|}
$$

The quantity, $\sum_{i}\left|\Delta \rho_{c_{j}}\right|$, is the best estimate for $\sum\left|\Delta \rho_{m_{i}}\right|$ available. It gives an over-all magnitude of the reactivity ${ }^{i}$ changes involved relative to which a difference can be computed. Equation (II) can be used at least as a supplement to, if not a substitute for, Equation (9). 
Most of the calculated reactivities for both reactors have fractional differences of less than \pm 0.13 . A few interesting cases including the exceptions are discussed below.

Water: The calculated reactivity for water compares fairly well with the measured value in ARMF-I but very poorly in ARMF-II. The discrepancy in ARMF-II may be largely because the reactivity for water is the difference between two very large effects. The relative difference given by Equation (9) is +1.99 , whereas when Equation (11) is used the difference is +0.089 . An increase of $21 \%$ for the thermal absorption contribution would bring the calculated and measured results into agreement. Perhaps changes in the group structure would help to correct the discrepancy; it is also likely that a transport calculation is required to calculate properly the reactivity of water.

Beryllium: Beryllium is very interesting because of the variety of neutron interactions it can undergo. The calculations indicate that the threshold $n, \alpha$ and $n, 2 n$ reactions are both significant, even in ARMF-I. However, agreement with the measured value in ARMF-I is poor. The difference as given by Equation (1l) is 0.2 . It seems likely that the positive $\mathrm{n}, 2 \mathrm{n}$ contribution is considerably overestimated. For this reason the excellent agreement in ARMF-II is suspect and may be fortuitous.

Magnesium: Calculated magnesium reactivity is excessively negative for both reactors. The net scatter and thermal absorption reactivities do not seem to be greatly out of line; it would thus appear that input epithermal cross sections are far too high. However, in ARMF-II, even if the epithermal contribution could be totally ignored, the calculated net reactivity would still be too 
negative by over $8 \mu \mathrm{k}$. This implies that the magnitude of the scatter reactivity is somewhat low or thermal absorption too high.

\section{Zirconium: Calculations also overestimate the epithermal}

absorption reactivity, if one assumes that the scatter and thermal absorption reactivities are approximately correct. This is no doubt a result of two factors: (I) no calculation is made for resonance self-shielding in GAM-1 for this element; (2) the GAM-1 cross-section library entries for zr are very high whon judged by wure recently published resonance parameters.'

Helium-3: The helium-3 calculations provide an excellent indication of the ability of the calculational models to predict thermal. reactivities. The ARMF-I calculation overestimates the magnitude of the $1 / v$ rèsponse by about $13 \%$. This could imply that the AIM-6 calculated real flux is somewhat too soft or that the input cross sections were obtained from too soft a spect.rum. The ARMF-II rcoult shows good agreement with experiment.

A possibility exiota for a similfuant blas in values of meagured relallve to calculated reactivities. The measurements of the regulating rod positions are converted to absolute values of reactivity by means of the inhour equation, which in this application assumes the form

$$
\rho=\frac{\Lambda}{T}+\sum_{i} \frac{\varepsilon_{i} \beta_{i}}{I+\lambda_{i} T} \simeq \varepsilon \sum_{i} \frac{\beta_{i}}{I+\lambda_{i}{ }^{\prime \prime}}
$$

where $\Lambda$ = effective neutron lifetime

$\beta_{i}=$ delayed neutron fraction of $i-t h$ precursor

$\varepsilon_{i}=$ a factor which makes the product $\varepsilon_{i} \beta_{i}$ equal to the effective delayed neutron fraction, $\bar{\beta}_{i}$, of the $i-t h$ precursor 
$\lambda_{i}=$ half-life of the $i-t h$ precursor

$\mathrm{T}=$ stable reactor period.

This expression is dependent upon two parameters, $\Lambda$ and $\bar{\beta}_{i}$, which can only be determined experimentally as a ratio. Thus, their assumed individual values needed in making calculations of $\rho$ will be based either on calculation or an "informed" estimate of at least one of the quantities. Such calculations or estimates will be subject to the usual errors. Thus, even the "measured" value has a calculated component.

In addition, Putnam shows ${ }^{(5)}$ that expressions for $\Lambda$, and $\bar{B}_{i}$ contain the same arbitrary factor, $\lambda_{c}^{m} \lambda^{n}$, which requires that the values of $\Lambda$ and $\bar{\beta}_{i}$ in the inhour equation be consistent with the chosen definition of reactivity. For the magnitude of the period commonly used in scaling the ARMF regulating rod calibrations (about 60 seconds or greater) the contribution of $\frac{\Lambda}{\mathrm{T}}$ to $\rho$ in Equation (12) becomes negligibly small $(<0.1 \%)$. Furthermore, since the individual values of $\varepsilon_{i}$ are not too different and not well known, the same value, $\varepsilon$, is assumed for ali groups. Thus, for practical purposes, for given experimental values of the $B_{i}, \Lambda_{i}$ and $T, \rho$ is directly proportional to $\varepsilon$, as given in the approximate form of $\rho$ in Equation (12). Since $\varepsilon$ is not well known, an error of several per cent is entirely probable in this quantity. It is recognized that this makes comparison of measured and calculated reactivities subject to possible bias. The scope of this report does not permit a detailed analysis of this problem. It should be noted that the length correction factor could also either introduce a bias or fortuitously cancel any bias arising 
from a poor value for $\varepsilon$. However, comparing measured and calculated sample reactivities [see Figures (11) and (12)], no significant bias is obvious.

It must be recognized that the calculation of a void in diffusion theory. is not possible in a rigorous manner. The method employed here, that of allowing no leakage either from the void or sample calculations, is only one of several possible compromise solutions to this fundamental problem. The improper handling of the void can result in errors of two types. The flux distributions may be incorrectly calculated to some degree; and, the reference level. represented by the void may be biased relative to the sample calculations. However, the generally good agreement of the calculations with experiment, il. resints seem to indicate that this is not a major source of error.

\section{SUMMARY AND CONCLUSIONS}

The results of the reactivity calculations indicate that the diffusion approximation can be used with considerable assurance in the analysis of AKMF measurements. Calculated reactivities compare fairly, well with measured values for a class of materials ranging from nearly pure inelastic scatterers (e.g., Bi) and a nearly pure elastic scatterer $\left(\mathrm{D}_{2} \mathrm{O}\right)$, to an essentially pure thermal absorber $\left({ }^{3} \mathrm{He}\right)$. In some cases where significant deviations occur the principal cause appears to be due to inadequate input cross sections ( $\mathrm{Mg}$ and $\mathrm{Zr}$ ). Beryllium and water alone appear to give anomalous results. In the case of beryllium a combination of changes in input cross sections and group structure might bring the ARMF-I results into line. The same is probably true for water in ARMF-II though a transport calculation may be required to obtain significant improvement. 
The importance of group structure in the calculation of scatter reactivities for the ARMF-II is clearly demonstrated. The improvement between the 4-group and 18-group calculations is unmistakable. It is quite probable that even more groups should be concentrated in the fission energy range for both reactors to obtain the best possible results for scatter and $n, 2 n$ reactions.

The calculations also show that both reactors are relatively insensitive to reactions in the $1 / \mathrm{E}$ range (say 0.5 to $10,000 \mathrm{eV}$ ), though this has been well known. Scattering reactions in the fission range tend to dominate net scatter reactivities, and thermal absorption dominates absorption reactivities. For this reason fewer groups in the $1 / E$ energy range would suffice for all but strong resonance absorbers.

Some improvement in the thermal calculation for ARMF-I could no doubt be obtained if one were to use a multi-thermal group model with. allowance for upscatter. With such changes reasonably accurate calculation of the reactivities of fissionable materials may be possible with the diffusion approximation.

It. is important to emphasize the relatively high sensitivity to scattering reactions in the fission energy range, particularly in the ARME-II. In that react or more than $78 \%$ of the scatter reactivity for all materials heavier than water results from reactions which originate in energies equal to or greater than that corresponding to group 4 ('Lower limit, 0:183. MeV). This fact had not previously been known. 


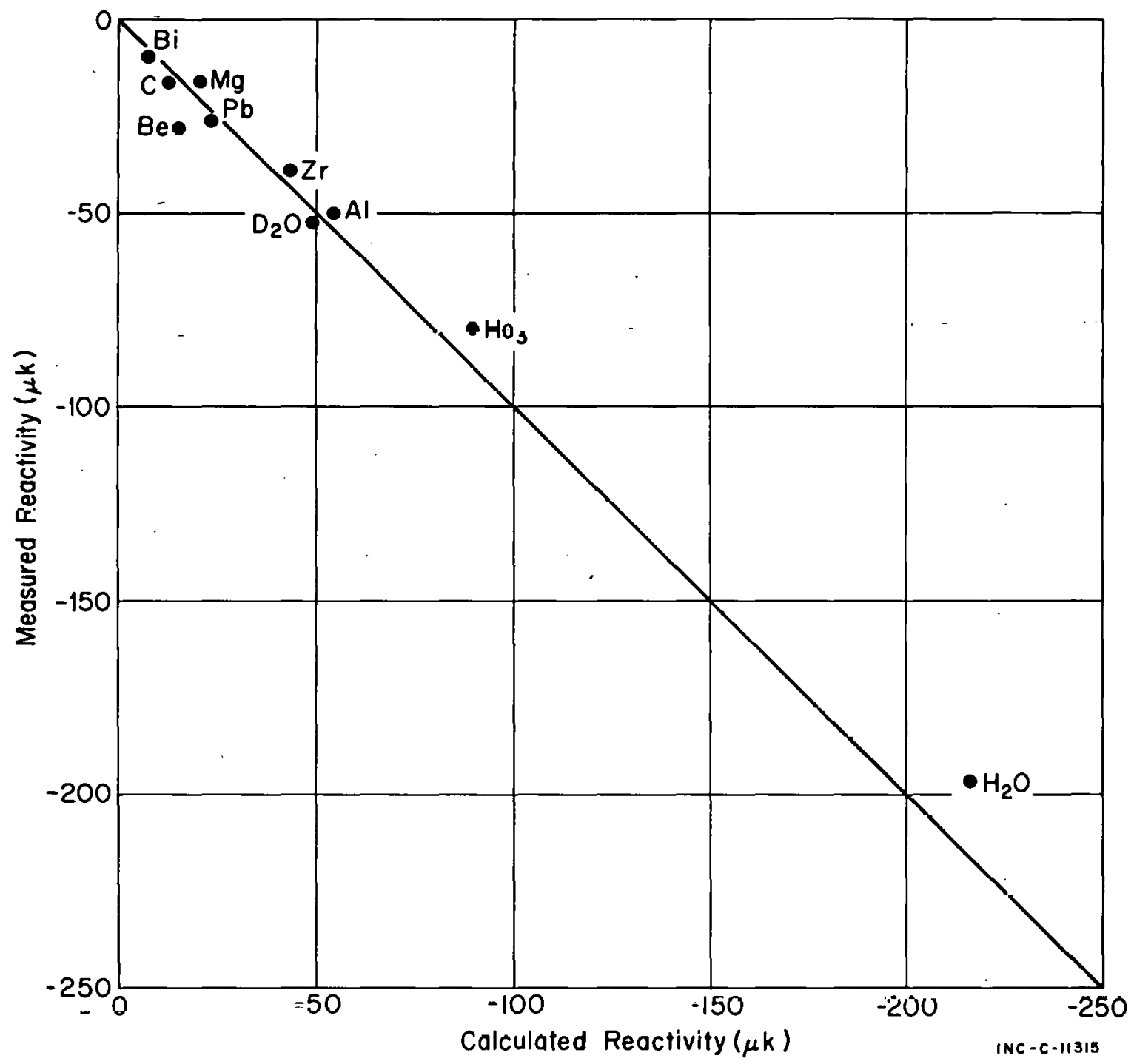

Figure 11 - Measured vs. Calculated Reactivities, ARMF-I 


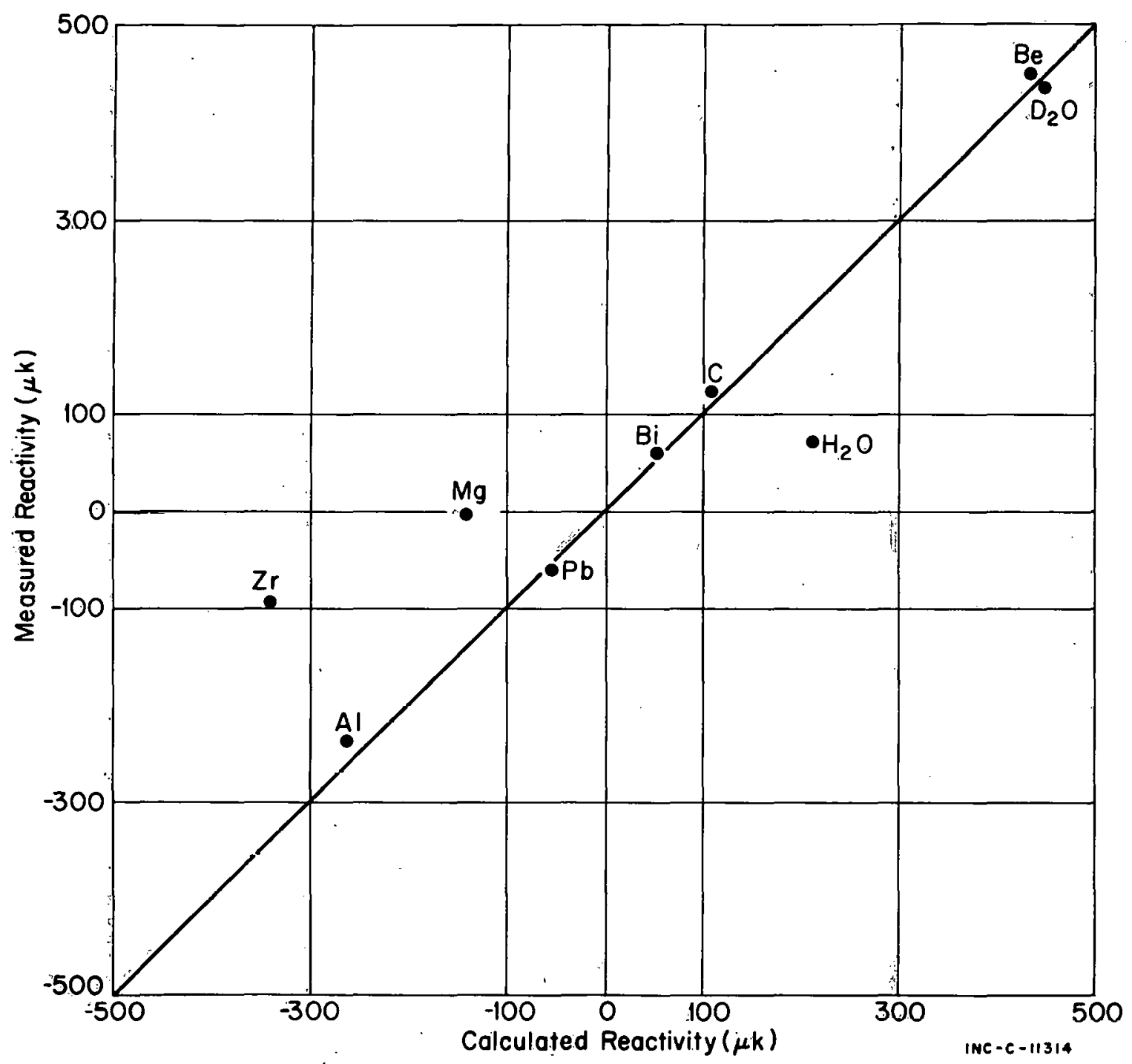

Figure 12 - Mensurph va. Ral silated Reactivities, ARMT=II 


\section{TABLE VIII}

\section{GROUP CROSS SECTIONS ${ }^{[a]}$ AND REACTIVITIES -- WATER \\ ARMF-I}

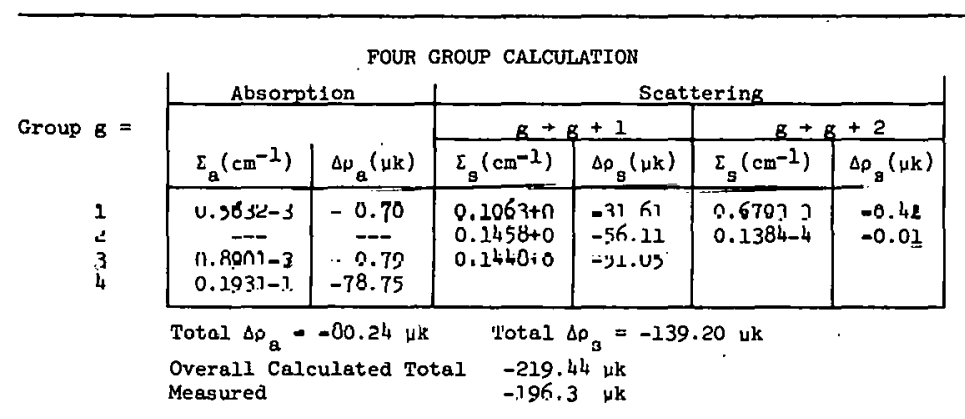

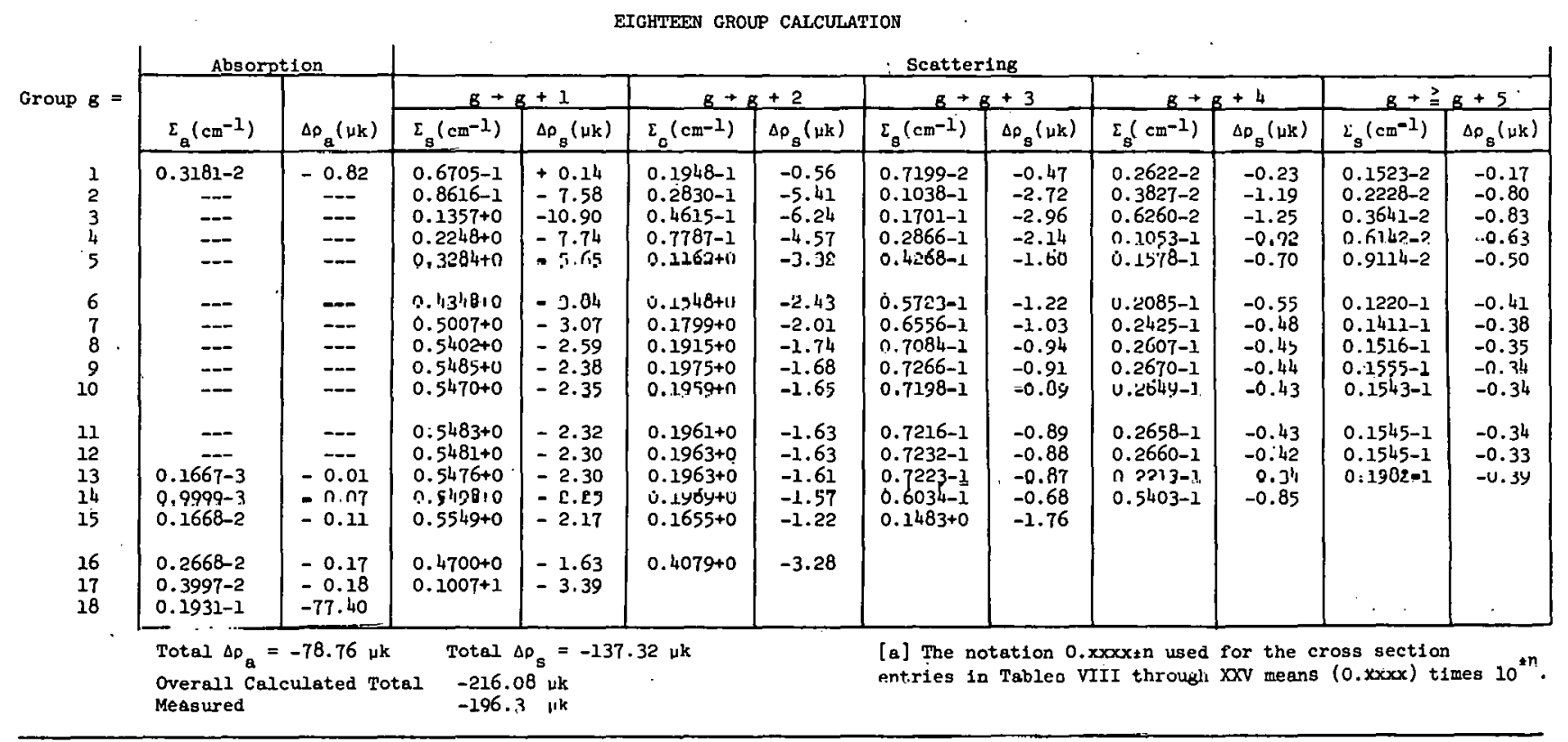


TABLE IX

GROUP CROSS SECTIONS $^{[a]}$ AND REACTIVITIES. -- HEAVY WATER.
ARMF-I

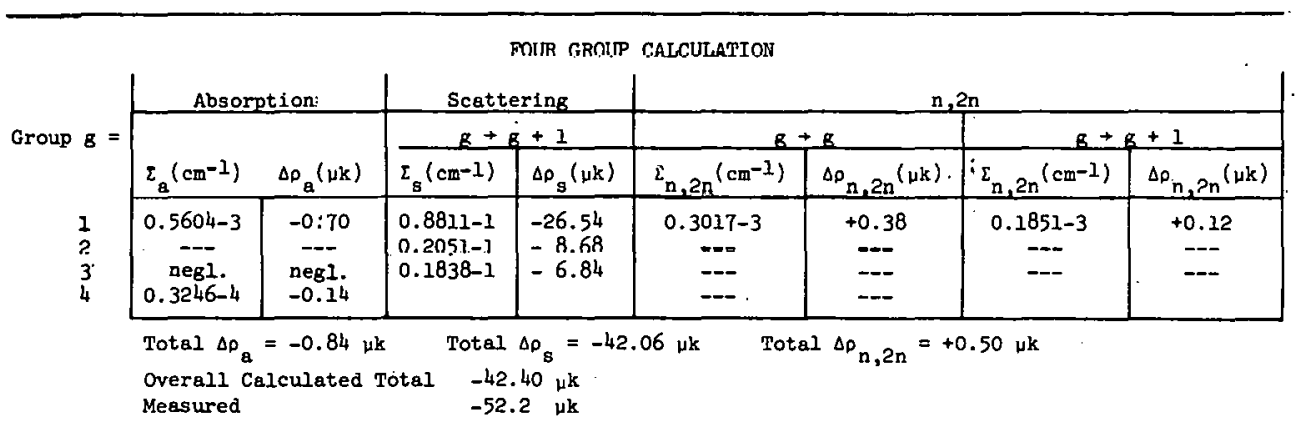

\begin{tabular}{|c|c|c|c|c|c|c|c|c|}
\hline & & & EICHTEEN & REUF & EATILUY & & & \\
\hline & Absor & etion: & & & Scat & $\operatorname{erlng}$ & & \\
\hline Group $8=$ & & & & \pm 1 & $g+$ & +2 & $B+$ & +3 \\
\hline & $\Sigma_{a^{(}}\left(\mathrm{cm}^{-1}\right)$ & $\Delta p_{g}(\mu \mathbf{k})$ & $\Sigma_{\mathrm{s}}\left(\mathrm{cm}^{-1}\right)$ & $\Delta \rho_{\mathrm{s}}(\mu \mathrm{k})$ & $\Sigma_{\mathrm{s}}\left(\mathrm{cm}^{-1}\right)$ & $\Delta \rho_{8}(\mu \mathrm{k})$ & $\Sigma_{\mathrm{s}}\left(\mathrm{cm}^{-1}\right)$ & $\Delta \rho_{\mathrm{g}}(\mathrm{\mu k})$ \\
\hline $\begin{array}{l}1 \\
2\end{array}$ & $0.3181-2$ & -0.83 & $\begin{array}{l}0.5283-1 \\
0.7600-1\end{array}$ & $\begin{array}{l}+0.11 \\
-6.73\end{array}$ & $0.2188-1$ & $\begin{array}{l}-0.633 \\
-6.65\end{array}$ & $\begin{array}{l}0.1231-2 \\
0.7512-2\end{array}$ & $\begin{array}{l}-0.0 \mathrm{~B} \\
-0.20\end{array}$ \\
\hline $\begin{array}{l}2 \\
3\end{array}$ & $=$ & $\overline{---}$ & $0.1104+0$ & $\begin{array}{l}-6.13 \\
-9.11\end{array}$ & $0.3714-1$ & $\begin{array}{l}-0.16 \\
-5.16\end{array}$ & $0.5678-3$ & -0.10 \\
\hline $\begin{array}{l}4 \\
5\end{array}$ & --- & --- & $\begin{array}{l}0.1184+0 \\
0.1132+0\end{array}$ & $\begin{array}{l}-4.53 \\
-2.23\end{array}$ & $\begin{array}{l}0.3064-1 \\
0.2829-1\end{array}$ & $\begin{array}{l}-2.00 \\
-0.92\end{array}$ & $\begin{array}{l}0.5159-3 \\
0.5074-3\end{array}$ & -0.01 \\
\hline & & & & & & & & \\
\hline 6 & -- & --- & $0.1142+0$ & -1.14 & $0.2902-1$ & -0.51 & $0.5750-3$ & -0.01 \\
\hline $\begin{array}{l}7 \\
8\end{array}$ & -- & --- & $\begin{array}{l}0.1155+0 \\
0.1168+0\end{array}$ & $\begin{array}{l}-0.78 \\
-0.61 \\
-0.6\end{array}$ & $\begin{array}{l}0.2963-1 . \\
0.2958-1\end{array}$ & $\begin{array}{l}-0.30 \\
-0.29 \\
-0.29\end{array}$ & $\begin{array}{l}0.3811-3 \\
0.6196-3\end{array}$ & $\begin{array}{l}-0.01 \\
-0.01 \\
-0.01\end{array}$ \\
\hline 9 & $\ldots$ & -- & $0.1172+0$ & -0.55 & $0.3023-1$ & -0.28 & $0.6559-3$ & -0.01 \\
\hline 10 & $\cdots$ & -- & $0.1169+0$ & -0.54 & $0.3001-1$. & -0.27 & $0: 6326-3$ & -0.01 \\
\hline 11 & $\cdots$ & -- & $0.11 \% 1+0$ & -0.53 & $0.2999=1$ & -0.27 & $0.6366-3$ & -0.01 \\
\hline $\begin{array}{l}12 \\
13\end{array}$ & $0: 3696-6$ & negl. & $\begin{array}{l}0.11171+0 \\
0.11 \%(0+0\end{array}$ & $\begin{array}{l}-0.52 \\
-0.52 \\
\text {. }\end{array}$ & $\begin{array}{l}0.3006-1 \\
0.3006-1 .\end{array}$ & $\begin{array}{l}-0.26 \\
-0.26\end{array}$ & $\begin{array}{l}0.6413-3 \\
0.6394-3\end{array}$ & $\begin{array}{l}-0.01 \\
-0.01\end{array}$ \\
\hline 14. & $0.2218-5$ & negl. & $0: 1169+0$ & -0.51 & $0.2995-1$ & -0.25 & $0.6027-3$ & -0.01 \\
\hline 15 & $: 0.3699-5$ & negt.. & $0.1170+0$ & -0.48 & $0.2734-1$ & -0.21 & $0.3349-2$ & -0.04 \\
\hline $\begin{array}{l}.16: \\
17\end{array}$ & $\begin{array}{c}0.5918: 5 \\
0.8865-5\end{array}$ & $\begin{array}{l}\text { neg1.. } \\
\text { neg1.. }\end{array}$ & $\begin{array}{l}0.9997-L^{*} \\
0.1701+0\end{array}$ & $\begin{array}{l}-0.37 \\
-0.61\end{array}$ & $0.4767-1$ & {$[,-0.40$} & & \\
\hline & & -0.13 & & & & & & \\
\hline
\end{tabular}

Overall Calculated-Total $\quad-49.30 \mu \mathrm{k}$

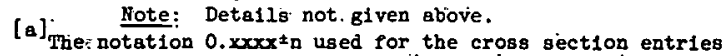
Measured $-49.30 \mu \mathrm{k}$
$-52.2 \mu \mathrm{k}$. in Tabies VIII through XXV means $(0.000 x)$ times $10^{ \pm n}$ 
TABLE X

GROUP CROSS SECTIONS ${ }^{[\nexists]}$ AIND REACT-VITIES -- BERYLLIUM ARMF-I

\begin{tabular}{|c|c|c|c|c|c|c|c|c|}
\hline \multirow{4}{*}{ Group $B=$} & \multicolumn{8}{|c|}{ - FOUR GRCUP CALCULALION } \\
\hline & \multicolumn{2}{|c|}{ Absorption } & \multirow{2}{*}{\multicolumn{2}{|c|}{$\frac{\text { Scat-ering }}{\varepsilon+g+1}$}} & \multicolumn{4}{|c|}{$n_{3} 2 n$} \\
\hline & \multirow[b]{2}{*}{$\Sigma_{\mathrm{a}}(\mathrm{cm}-1)$} & \multirow[b]{2}{*}{$\Delta \varepsilon_{a}(u k)$} & & & \multicolumn{2}{|c|}{$B+B$} & \multicolumn{2}{|c|}{$\beta+\beta+1$} \\
\hline & & & $\varepsilon_{\mathrm{s}}\left(\mathrm{cm}^{-1}\right)$ & $\Delta o_{\mathrm{s}}(\mu \mathrm{k}$ & $\Sigma_{n, 2 n}(\mathrm{cmr})^{-1)}$ & $\Delta p_{n, 2 n^{\prime}(n)}$ & $\varepsilon_{n, 2 n}\left(-m^{-1}\right)$ & $\Delta p_{n, 2 n}(\mu k)$ \\
\hline \multirow[t]{2}{*}{$\begin{array}{l}1 \\
2 \\
3 \\
3 \\
4\end{array}$} & $\begin{array}{c}0.5772-2 \\
-\overline{-} \\
0.1071-2\end{array}$ & $\begin{array}{c}-7.66 \\
--- \\
-- \\
-4.53\end{array}$ & $\begin{array}{l}0.3643-1 \\
0.1630-1 \\
0.1475-1\end{array}$ & $\begin{array}{l}-11.45 \\
=-6.89 \\
-5.56\end{array}$ & $\begin{array}{c}0.1484-1 \\
-- \\
=-\end{array}$ & $\begin{array}{c}+19.62 \\
-- \\
--\end{array}$ & $\begin{array}{c}0 . \text { i } 492-2 \\
-- \\
-\end{array}$ & $\begin{array}{c}+3.80 \\
---\end{array}$ \\
\hline & $\begin{array}{l}\text { Total } \Delta \rho_{a} \\
\text { Overall } \\
\text { Measared }\end{array}$ & $\begin{array}{l}-12.19 \\
\text { culated }\end{array}$ & $\begin{array}{cc} & \text { Tota } \\
\text { tal } & -12 \\
-27\end{array}$ & $\begin{array}{l}\Delta p_{\mathrm{s}}= \\
67 \mu \mathrm{k} \\
.5 \mu \mathrm{k}\end{array}$ & $0 \mu \mathrm{k}$ & $\Delta \cdot_{n, a n}=$ & $3 . \therefore 2 \mu \mathrm{E}$ & \\
\hline
\end{tabular}

to

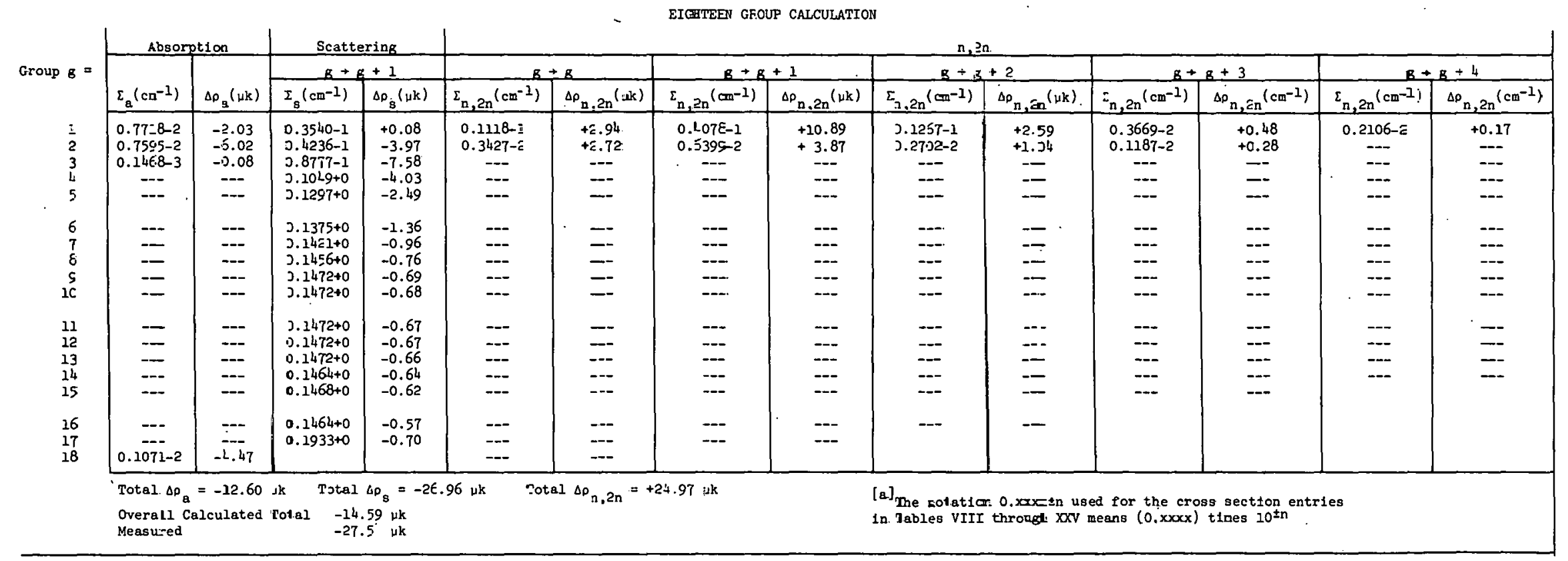


TABLE XI

GROUP CROSS SECTIONS ${ }^{[a]}$ AND REACTIVITIES -- CARBON ARMF-I

EIGHTEEN GROUP CALCULATION

\begin{tabular}{|c|c|c|c|c|c|c|c|c|c|c|}
\hline \multirow{3}{*}{ Group $B=$} & \multicolumn{2}{|c|}{ Absorption. } & \multicolumn{8}{|c|}{ Scattering } \\
\hline & \multirow[b]{2}{*}{$\Sigma_{\mathrm{a}}\left(\mathrm{cm}^{-1}\right)$} & \multirow[b]{2}{*}{$\Delta \rho_{\mathrm{a}}(\mu \mathrm{k})}$. & \multicolumn{2}{|c|}{$g+6+1$} & \multicolumn{2}{|c|}{$8+8+2$} & \multicolumn{2}{|c|}{$8+8+3$} & \multicolumn{2}{|c|}{$8+8+4$} \\
\hline & & & $\Sigma_{\mathrm{s}}\left(\mathrm{cm}^{-1}\right)$ & $\Delta \rho_{g}(\mu k)$ & $\varepsilon_{g}\left(\mathrm{~cm}^{-1}\right)$ & $\Delta o_{g}(u k)$ & $\varepsilon_{\mathrm{g}}\left(\mathrm{cm}^{-1}\right)$ & $\Delta p_{8}(u k)$ & $\Sigma_{\mathrm{s}}\left(\mathrm{cm}^{-1}\right)$ & $\Delta \rho_{g}(u k)$ \\
\hline $\begin{array}{l}1 \\
2 \\
3 \\
4 \\
5\end{array}$ & $\begin{array}{l}-- \\
\overline{--} \\
\overline{--}\end{array}$ & $\begin{array}{l}- \\
- \\
- \\
-\end{array}$ & $\begin{array}{l}0.4496-1 \\
0.2696-1 \\
0.3527-1 \\
0.4661-1 \\
0.5 .505-1\end{array}$ & $\begin{array}{l}+0.10 \\
-2.46 \\
-2.97 \\
-1.69 \\
-1.00\end{array}$ & $\begin{array}{c}0.2166-2 \\
= \\
= \\
\therefore-\end{array}$ & $\begin{array}{c}-0.06 \\
-- \\
-- \\
-- \\
--\end{array}$ & $\begin{array}{c}0.7713-3 \\
- \\
= \\
= \\
-\end{array}$ & $\begin{array}{c}-0.05 \\
-- \\
-- \\
--\end{array}$ & $\begin{array}{c}0.1539-3 \\
-- \\
=- \\
= \\
--\end{array}$ & $\begin{array}{c}-0.01 \\
=1 \\
=\end{array}$ \\
\hline $\begin{array}{r}6 \\
7 \\
8 \\
9 \\
9 \\
10\end{array}$ & $\begin{array}{l}= \\
\overline{-} \\
=\end{array}$ & $\begin{array}{l}=- \\
\ddot{-} \\
=\end{array}$ & $\begin{array}{l}0.5827-1 \\
0.6133-1 \\
0.6342-1 \\
0.6431-1 \\
0.6439-1\end{array}$ & $\begin{array}{l}-0.55 \\
-0.40 \\
-0.32 \\
-0.29 \\
-0.29\end{array}$ & $\begin{array}{l}= \\
= \\
=\end{array}$ & $\begin{array}{l}- \\
= \\
=\end{array}$ & $\begin{array}{l}- \\
\overline{-} \\
-\end{array}$ & $\begin{array}{l}= \\
=- \\
= \\
--\end{array}$ & $\begin{array}{l}-- \\
= \\
=\end{array}$ & $\begin{array}{l}- \\
= \\
=\end{array}$ \\
\hline $\begin{array}{l}11 \\
1: 2 \\
13 \\
14 \\
15\end{array}$ & $\begin{array}{l}\overline{-} \\
\overline{-} \\
=\end{array}$ & $\begin{array}{l}= \\
= \\
=\end{array}$ & $\begin{array}{l}0.6439-1 \\
0.61130-1 \\
0.6437-1 \\
0.6399-1 \\
0.6420-1\end{array}$ & $\begin{array}{l}-0.28 \\
-0.78 \\
-0.28 \\
-0.27 \\
-0.26\end{array}$ & $\begin{array}{l}- \\
-- \\
--\end{array}$ & $\begin{array}{l}-- \\
\cdots \\
-- \\
--\end{array}$ & $\begin{array}{l}-- \\
\cdots \\
-- \\
-\end{array}$ & $\begin{array}{l}- \\
- \\
- \\
-\end{array}$ & $\begin{array}{l}- \\
\bar{z} \\
\overline{-}\end{array}$ & $\begin{array}{l}-- \\
=- \\
= \\
-\end{array}$ \\
\hline $\begin{array}{l}1.6 \\
17 \\
18:\end{array}$ & $=\overline{=}$ & $\overline{-1.14}$ & $\begin{array}{l}0.6398-1 \\
0.8436-1\end{array}$ & $\begin{array}{l}-0.23 \\
-0.30\end{array}$ & $\ddot{--}$ & -- & $\cdots$ & $\overline{-}$ & $=$ & $=$ \\
\hline & $\begin{array}{l}\text { Total } \Delta p_{a}= \\
\text { Overall Cal } \\
\text { Measured }\end{array}$ & $\begin{array}{l}14 \mu \mathrm{k} \\
\text { ated Tota }\end{array}$ & $\begin{array}{c}\text { Total } \Delta p_{\mathrm{s}}= \\
-13.03 . \mu \mathrm{k} \\
-15.8 \mu \mathrm{k}\end{array}$ & j.k & $\begin{array}{l}{[a] \text { The no }} \\
\text { in Tables. }\end{array}$ & $\begin{array}{l}0 . x 000 \\
\text { through }\end{array}$ & $\begin{array}{l}\text { used.for } \\
V \text { means }\end{array}$ & $\begin{array}{l}\text { crossi. } \\
x x) \text { tif }\end{array}$ & $\operatorname{lon}_{10^{ \pm n}}$ entries & \\
\hline
\end{tabular}


TABLE XII

GROUP CROSS SECTIONS ${ }^{[a]}$ AND REACTIVITIES -- MAGNESIUM
ARMF-I

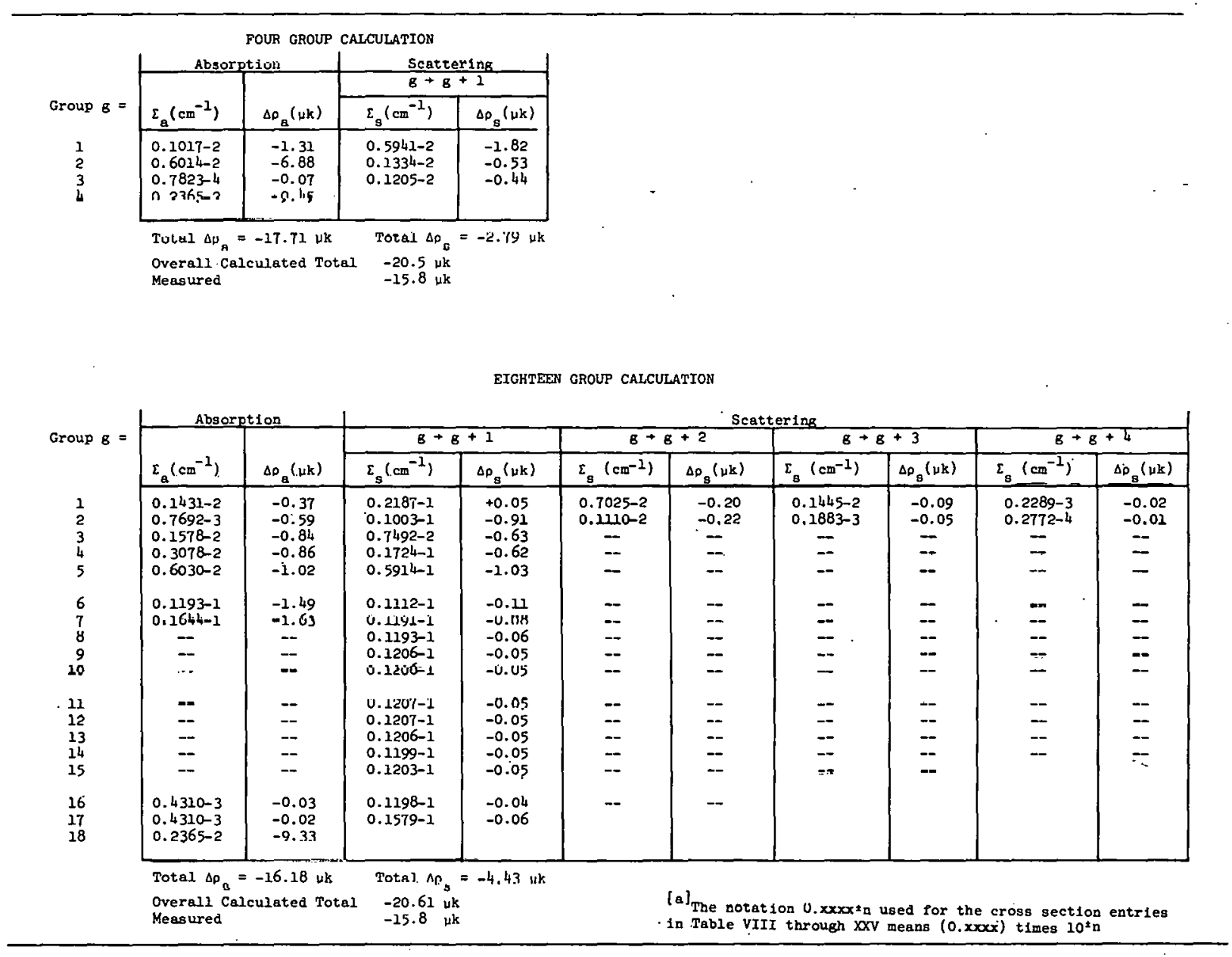




\section{TABLE XIII}

\section{GROUP CROSS SECTIONS ${ }^{[a]}$ AND REACTIVITIES -- ALUMINUM ARMF-I}

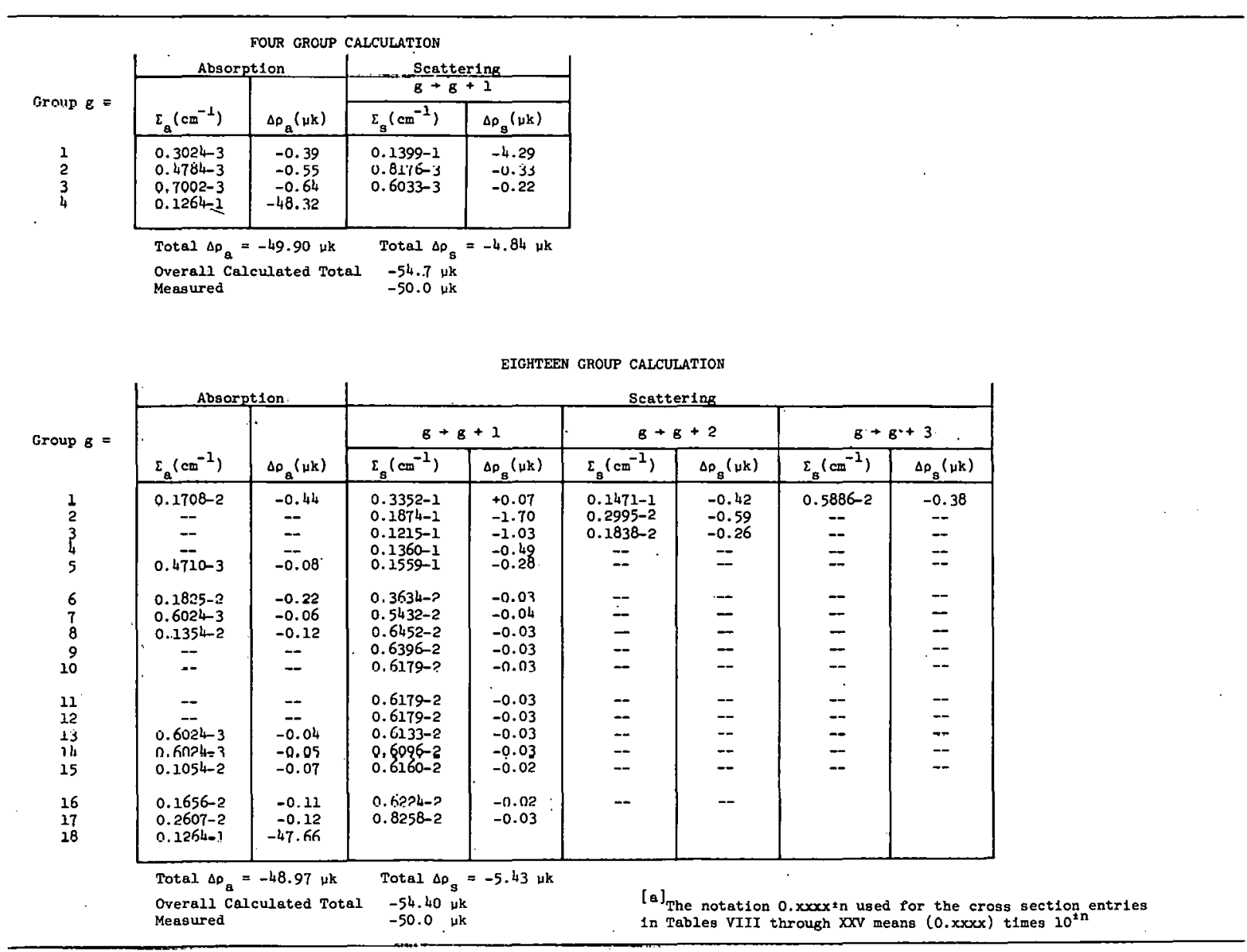




\section{TABLE XIV}

\section{GROUP CROSS SECTIONS ${ }^{[a]}$ AND REACTIVITIES -- ZIRCONIUM ARMF-I}

\begin{tabular}{|c|c|c|c|c|}
\hline \multirow{3}{*}{ Group $\mathrm{g}=$} & \multicolumn{4}{|c|}{ FOUR GROUP CALCULATIOH } \\
\hline & \multicolumn{2}{|c|}{ Absorption } & \multicolumn{2}{|c|}{ Scattering } \\
\hline & $\varepsilon\left(\mathrm{cm}^{-1}\right)$ & $\Delta D^{\prime}(\mu k)$ & $\frac{\mathrm{g}}{2 \cdot\left(\mathrm{cm}^{-2}\right)}$ & 1 \\
\hline \multirow{4}{*}{1} & $0,5 \times 1 \%-4$ & -0.07 & $0,2448-1$ & -4.55 \\
\hline & $\theta_{i} \angle L T Y=i$ & $=-1+30$ & $0.0328-3$ & -0.34 \\
\hline & $0.1067-1$ & -9.93 & U. $4 / R 9=3$. & \\
\hline & $\begin{array}{l}\text { Tnt:al Ar } \\
\text { UNerall } \\
\text { Measured }\end{array}$ & $0.37 \mathrm{r}$ & \multicolumn{2}{|c|}{$\begin{array}{l}\text { Tulal } \Delta \omega_{\mathrm{H}}=-9.10 \mu \mathrm{k} \\
-45.47 \mu \mathrm{k} \\
-38.7\end{array}$} \\
\hline
\end{tabular}

\begin{tabular}{|c|c|c|c|c|c|c|c|c|c|c|c|c|}
\hline \multirow{4}{*}{ Group $8=$} & \multicolumn{12}{|c|}{ EIGHTEEN GROUP CALCULATION } \\
\hline & \multicolumn{2}{|c|}{ Absorption } & \multicolumn{10}{|c|}{ Scattering } \\
\hline & \multirow[b]{2}{*}{$\varepsilon_{a}\left(\mathrm{~cm}^{-1}\right)$} & \multirow[b]{2}{*}{$\Delta \rho_{\mathrm{a}}(u k)$} & \multicolumn{2}{|c|}{$B+B+1$} & \multicolumn{2}{|c|}{$B+B+2$} & \multicolumn{2}{|c|}{$8+8+3$} & \multicolumn{2}{|c|}{$8+8+4$} & \multicolumn{2}{|c|}{$8+8+5$} \\
\hline & & & $\varepsilon_{\mathrm{g}}\left(\mathrm{cm}^{-1}\right)$ & $\Delta 0_{8}(u k)$ & $\Sigma_{\mathrm{s}}\left(\mathrm{cm}^{-1}\right)$ & $\Delta \rho_{\mathrm{s}}(u k)$ & $\Sigma_{8}\left(\mathrm{cw}^{-1}\right)$ & $\Delta v_{\mathrm{g}}(u k)$ & $2_{\mathrm{g}}\left(\mathrm{cm}^{-2}\right)$ & $\Delta 0_{\mathrm{s}}(\mathrm{Hk})$ & $\varepsilon_{\mathrm{s}}\left(\mathrm{cm}^{-1}\right)$ & $\Delta 0_{\mathrm{g}}(\mu \mathrm{k})$ \\
\hline $\begin{array}{l}1 \\
2 \\
3 \\
4 \\
5\end{array}$ & $\begin{array}{c}\overline{-} \\
0.3100-3 \\
0.7467-3 \\
0.1485-2\end{array}$ & $\begin{array}{l}-- \\
-0.17 \\
-0.22 \\
-0.27\end{array}$ & $\begin{array}{l}0.4464-1 \\
0.2693-1 \\
0.6827-2 \\
0.6252-2 \\
0.6758-2\end{array}$ & $\begin{array}{l}+0.10 \\
-2.50 \\
-0.60 \\
-0.23 \\
-0.12\end{array}$ & $\begin{array}{c}0.1181-1 \\
0.5375-2 \\
0.1557-3 \\
-- \\
--\end{array}$ & $\begin{array}{l}-0.34 \\
-1.08 \\
-0.02 \\
- \\
=-\end{array}$ & $\begin{array}{c}0.5129-2 \\
0.4377-3 \\
-- \\
-\end{array}$ & $\begin{array}{l}-0.34 \\
-0.12 \\
-- \\
=-\end{array}$ & $\begin{array}{c}0.1107-2 \\
= \\
= \\
=\end{array}$ & $\begin{array}{l}-0.10 \\
-- \\
-- \\
-- \\
--\end{array}$ & $\begin{array}{c}0.3966-3 \\
-- \\
-- \\
-- \\
--\end{array}$ & $\begin{array}{l}-0.04 \\
=- \\
=- \\
=\end{array}$ \\
\hline $\begin{array}{r}6 \\
7 \\
8 \\
9 \\
10\end{array}$ & $\begin{array}{l}0.2865-2 \\
0.5660-2 \\
0.1137-1 \\
0.2256-1 \\
0.3600-1\end{array}$ & $\begin{array}{l}-0.36 \\
-0.58 \\
-1.04 \\
-1.94 \\
-2.98\end{array}$ & $\begin{array}{l}0.7445-2 \\
0.6939-2 \\
0.6061-2 \\
0.5637-2 \\
0.4281-2\end{array}$ & $\begin{array}{l}-0.07 \\
-0.04 \\
-0.03 \\
-0.03 \\
-0.02\end{array}$ & $\begin{array}{l}-- \\
-- \\
-- \\
--\end{array}$ & $\begin{array}{l}=- \\
=- \\
=-\end{array}$ & $\begin{array}{l}=- \\
=- \\
=-\end{array}$ & $\begin{array}{l}= \\
=- \\
= \\
-\end{array}$ & $\begin{array}{l}=- \\
=- \\
=- \\
=-\end{array}$ & $\begin{array}{l}=- \\
=- \\
--\end{array}$ & $\begin{array}{l}=- \\
-- \\
-- \\
--\end{array}$ & $\begin{array}{l}- \\
= \\
=\end{array}$ \\
\hline $\begin{array}{l}11 \\
12 \\
13 \\
14 \\
15\end{array}$ & $\begin{array}{c}0.2892-1 \\
- \\
\overline{0.4298-3} \\
0.536 R=3\end{array}$ & $\begin{array}{l}-2.31 \\
-- \\
--0.03 \\
=0 \mathrm{nl}\end{array}$ & $\begin{array}{l}0.5796-2 \\
0.5796-2 \\
0.5793-2 \\
0.5758-2 \\
0.5779-2\end{array}$ & $\begin{array}{l}-0.02 \\
-0.03 \\
-0.03 \\
-0.02 \\
-0.02\end{array}$ & $\begin{array}{l}-- \\
-- \\
-- \\
=-\end{array}$ & $\begin{array}{l}=- \\
-- \\
-- \\
-\end{array}$ & $\begin{array}{l}-- \\
=- \\
=- \\
-\end{array}$ & $\begin{array}{l}-- \\
=- \\
=- \\
-\end{array}$ & $\begin{array}{l}=- \\
=-\end{array}$ & $\begin{array}{l}- \\
-- \\
--\end{array}$ & $\begin{array}{l}\therefore \\
--\end{array}$ & $\begin{array}{l}-- \\
-- \\
--\end{array}$ \\
\hline \multirow[t]{2}{*}{$\begin{array}{l}16 \\
17 \\
18\end{array}$} & $\begin{array}{l}0.9662-3 \\
0.1430-2 \\
0.6926-2\end{array}$ & $\begin{array}{r}-0.06 \\
-0.07 \\
-27.39\end{array}$ & $\begin{array}{l}0.5757-2 \\
0.7585-2\end{array}$ & $\begin{array}{l}-0.02 \\
-0.03\end{array}$ & -- & -- & & & & & & \\
\hline & $\begin{array}{l}\text { Tnt.s? } \Delta P_{\mathrm{a}} \\
\text { Overall } \mathrm{C} \\
\text { Measured }\end{array}$ & 37.16 & $\begin{array}{l}\text { Tulal } \\
-43.2 \\
-38.7\end{array}$ & $\rightarrow$ & & & notat & . & $\begin{array}{l}\text { for th } \\
\text { eans }(0 .\end{array}$ & $\begin{array}{l}\text { cross se } \\
\text { xx) t.ime }\end{array}$ & entries & \\
\hline
\end{tabular}




\section{TABLE XV}

\section{GROUP CROSS SECTIONS ${ }^{[a]}$ AND REACTIVITIES -- LEAD \\ ARMF-I}

\begin{tabular}{|c|c|c|c|c|}
\hline \multirow{3}{*}{ Group $8=$} & \multicolumn{4}{|c|}{ FOUR GROUP CALCUIATTON } \\
\hline & \multicolumn{2}{|c|}{ Absorption } & \multicolumn{2}{|c|}{ Scattering } \\
\hline & $\Sigma_{\mathrm{g}}\left(\mathrm{cm}^{-1}\right)$ & $\Delta p_{\mathrm{g}}(\mu \mathrm{k})$ & $\varepsilon_{\mathrm{g}}\left(\mathrm{cm}^{-1}\right)$ & $\Delta \rho_{g}(\mu \mathrm{k})$ \\
\hline \multirow[t]{2}{*}{1} & $\begin{array}{c}= \\
0.2416-3 \\
0.4881-2\end{array}$ & $\begin{array}{l}- \\
-0 \\
-0.22 \\
-19.13\end{array}$ & $\begin{array}{l}0.1112-1 \\
0.3895-3 \\
0.3544-3\end{array}$ & $\begin{array}{l}-3.38 \\
-0.15 \\
-0.13\end{array}$ \\
\hline & $\begin{array}{l}\text { Total } \Delta \rho_{\mathrm{a}} \\
\text { Overail } \mathrm{C} \\
\text { Measured }\end{array}$ & & $\begin{array}{r}\text { Total } \\
-23 \\
-26\end{array}$ & \\
\hline
\end{tabular}

BRIAHTFFN GROIP' CAIKCHLATTON

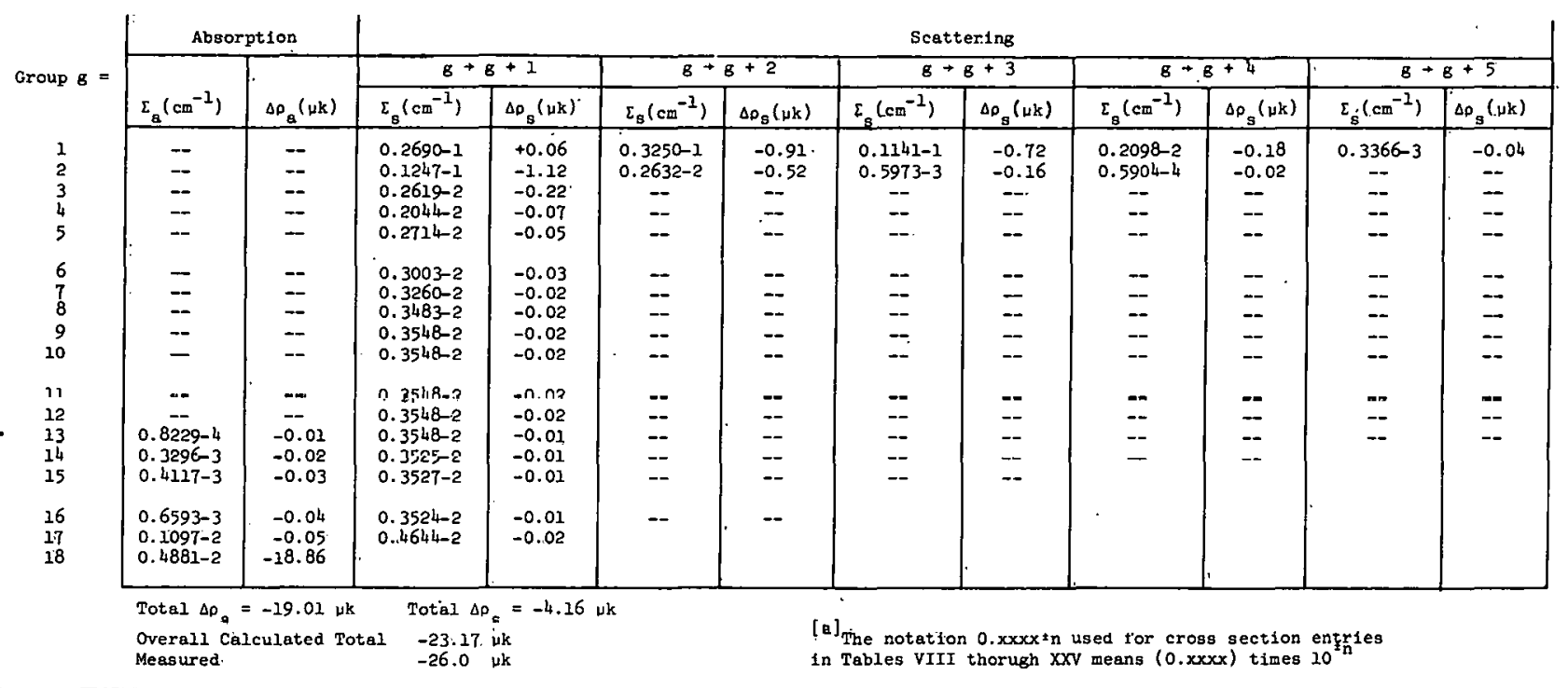




\section{TABLE XVI \\ GROUP CROSS SECTIONS ${ }^{[a]}$ AND REACTIVITIES -- BISMUTH \\ ARMF-I}

FOUR GROUP CALCULATION

\begin{tabular}{|c|c|c|c|c|c|c|c|c|}
\hline \multirow{3}{*}{ G̣roup $8=$} & \multicolumn{2}{|c|}{ Aosorption } & \multicolumn{2}{|c|}{ Scattering } & \multicolumn{4}{|c|}{$n, 2 n$} \\
\hline & \multirow[b]{2}{*}{$\Sigma_{a}\left(\mathrm{~cm}^{-1}\right)$} & \multirow[b]{2}{*}{$\Delta \rho_{A}(\mu k)$} & \multirow[b]{2}{*}{$\varepsilon_{\mathrm{g}}\left(\mathrm{cm}^{-1}\right)$} & \multirow[b]{2}{*}{$\Delta \dot{p}_{\mathrm{s}}(\mu \mathrm{k})$} & \multicolumn{2}{|c|}{$B+B$} & \multicolumn{2}{|c|}{$8+8+1$} \\
\hline & & & & & $\varepsilon_{n, i n}\left(n m^{-1}\right)$ & $\Delta \theta_{n}, 2_{n}(u k)$ & $\varepsilon_{n, 2 n}\left(u^{-1}\right)$ & $\Delta \Delta_{n, 2 n}(H k)$ \\
\hline \multirow[t]{2}{*}{$\begin{array}{l}1 \\
2 \\
3 \\
4\end{array}$} & $\begin{array}{c}\overline{-} \\
0.8508-3\end{array}$ & $\begin{array}{c}-. \\
-2 \\
-3.49\end{array}$ & $\begin{array}{l}0.1351-1 \\
0.2915-3 \\
0.2473=3\end{array}$ & $\begin{array}{l}-4.20 \\
-0.12 \\
-0.09\end{array}$ & $\begin{array}{c}0.5144-4 \\
=- \\
= \\
=\end{array}$ & $\begin{array}{c}+0.07 \\
-- \\
-- \\
--\end{array}$ & $\begin{array}{c}0.2781-4 \\
=- \\
=-\end{array}$ & $\begin{array}{c}+0.02 \\
\quad \ldots \\
--\end{array}$ \\
\hline & $\begin{array}{l}\text { Total } \Delta p \\
\text { Overall } \\
\text { Measured }\end{array}$ & ulat & $\begin{array}{r}\text { Total } \\
-7.81 \\
-9.3\end{array}$ & $=-$ & Total & $=+0.09$ & . & \\
\hline
\end{tabular}

EIGHTEEN GROUP CALCULATTON

\begin{tabular}{|c|c|c|c|c|c|c|c|c|c|c|c|c|}
\hline \multirow{3}{*}{ Group $\mathrm{g}=$} & \multicolumn{2}{|c|}{ Absorption } & \multicolumn{10}{|c|}{ Scattering } \\
\hline & \multirow{2}{*}{$E_{8}\left(\mathrm{~cm}^{-1}\right)$} & \multirow[b]{2}{*}{$\Delta \rho_{g}(u k)$} & \multicolumn{2}{|c|}{$8-8+1$} & \multicolumn{2}{|c|}{$B+8+2$} & \multicolumn{2}{|c|}{$8+8+3$} & \multicolumn{2}{|c|}{$8+8+4$} & \multicolumn{2}{|c|}{$8+8+5$} \\
\hline & & & $\Sigma_{\mathrm{g}}\left(\mathrm{cm}^{-1}\right)$ & $\Delta p_{g}(\mu k)$ & $\Sigma_{s}\left(\mathrm{~cm}^{-1}\right)$ & $\Delta p_{s}(\mu k)$ & $\Sigma_{\mathrm{g}}\left(\mathrm{cm}^{-1}\right)$ & $\Delta \rho_{g}(\mu k)$ & $\Sigma_{s}\left(\mathrm{~cm}^{-1}\right)$ & $\Delta \rho_{s}(u k)$ & $\Sigma_{g}\left(\mathrm{~cm}^{-1}\right)$ & $\Delta p_{g}(\mu k)$ \\
\hline $\begin{array}{l}1 \\
2 \\
3 \\
1 \\
5\end{array}$ & $\begin{array}{l}-- \\
-- \\
= \\
--\end{array}$ & $\begin{array}{l}-- \\
\cdots- \\
=- \\
--\end{array}$ & $\begin{array}{l}0.1635-1 \\
0.9494=2 \\
0.2294-2 \\
0.1816-1 \\
0.2257-2\end{array}$ & $\begin{array}{l}+0.04 \\
-0.86 \\
-0.20 \\
-0.07 \\
-0.04\end{array}$ & $\begin{array}{l}0.2968-1 \\
0.5534-2 \\
0.3617-.3 \\
=- \\
--\end{array}$ & $\begin{array}{l}=0.85 \\
-1.10 \\
=0.05 \\
=- \\
=-\end{array}$ & $\begin{array}{c}0.127 \mathrm{f}-1 \\
0.1419-2 \\
0.6392 \ldots h \\
=- \\
--\end{array}$ & $\begin{array}{l}-0.83 \\
-0.38 \\
-0.01 \\
-- \\
--\end{array}$ & $\begin{array}{l}0.271 G-2 \\
0.2451-3 \\
== \\
=- \\
=-\end{array}$ & $\begin{array}{c}=0.24 \\
-0.08 \\
- \\
--\end{array}$ & $\begin{array}{c}0.4350-3 \\
0.3633-4 \\
=- \\
=-\end{array}$ & $\begin{array}{c}-0.05 \\
-0.01 \\
-- \\
-- \\
-\end{array}$ \\
\hline $\begin{array}{r}6 \\
7 \\
8 \\
9 \\
10\end{array}$ & $\begin{array}{l}- \\
-- \\
-- \\
--\end{array}$ & $\begin{array}{l}=- \\
-- \\
=- \\
--\end{array}$ & $\begin{array}{l}0.2672-2 \\
0.2119-2 \\
0.2601-2 \\
0.2826-2 \\
0.2260-2\end{array}$ & $\begin{array}{l}-0.03 \\
-0.01 \\
-0.01 \\
-0.01 \\
-0.01\end{array}$ & $\begin{array}{l}-- \\
=- \\
=-\end{array}$ & $\begin{array}{l}-- \\
= \\
=- \\
-\end{array}$ & $\begin{array}{l}= \\
= \\
= \\
=\end{array}$ & $\begin{array}{l}= \\
= \\
= \\
=\end{array}$ & $\begin{array}{l}-- \\
-- \\
--\end{array}$ & $\begin{array}{l}-- \\
-- \\
-- \\
--\end{array}$ & $\begin{array}{l}= \\
= \\
= \\
=\end{array}$ & $\begin{array}{l}\overline{-} \\
\overline{-}\end{array}$ \\
\hline $\begin{array}{l}11 \\
20 \\
23 \\
14 \\
15\end{array}$ & $\begin{array}{l}-- \\
-- \\
-- \\
--\end{array}$ & $\begin{array}{l}-- \\
-- \\
-- \\
--\end{array}$ & $\begin{array}{l}0.2476-2 \\
0.2476-2 \\
0.2475-2 \\
0.2460-2 \\
0.2468-2\end{array}$ & $\begin{array}{l}-0.01 \\
-0.01 \\
-0.01 \\
-0.01 \\
-0.01\end{array}$ & $\begin{array}{l}\cdots \\
-- \\
-- \\
--\end{array}$ & $\begin{array}{l}-- \\
-- \\
-- \\
--\end{array}$ & $\begin{array}{l}=- \\
=- \\
=- \\
=-\end{array}$ & $\begin{array}{l}= \\
= \\
= \\
=\end{array}$ & $\begin{array}{l}-- \\
=- \\
--\end{array}$ & $\begin{array}{l}-- \\
=- \\
--\end{array}$ & $\begin{array}{l}= \\
=\end{array}$ & $=$ \\
\hline $\begin{array}{l}16 \\
17 \\
18\end{array}$ & $\begin{array}{c}= \\
0.8508-3\end{array}$ & $\begin{array}{l}-- \\
-3.40\end{array}$ & $\begin{array}{l}0.2459-2 \\
0.3240-2\end{array}$ & $\begin{array}{l}-0.01 \\
-0.02\end{array}$ & - & $m$ & & & & & - & \\
\hline
\end{tabular}

Total $\Delta D_{a}=-3.40 \mu \mathrm{k} \quad$ Total $\Delta p_{s}=-4.87 \mu \mathrm{k} \quad$ Total $\Delta \rho_{n, 2 n}(\operatorname{details}$ not given ahnve) $=+0.09 \mu \mathrm{k}$

Overall. Calculated Total $-8.18 \mu \mathrm{k}$

[a] The notation $0 . \times x \times x^{ \pm} n$ uocd for cross section entries Measured -9.3 uk

in Tables VIII through XXV mcans $(0 . x \mu r x)$ times $10^{t} \mathrm{n}$ 
TABLE XVII

GROUP CROSS SECTIONS ${ }^{[a]}$ AND REACTIVITIES -- 'WATER ARMF-II

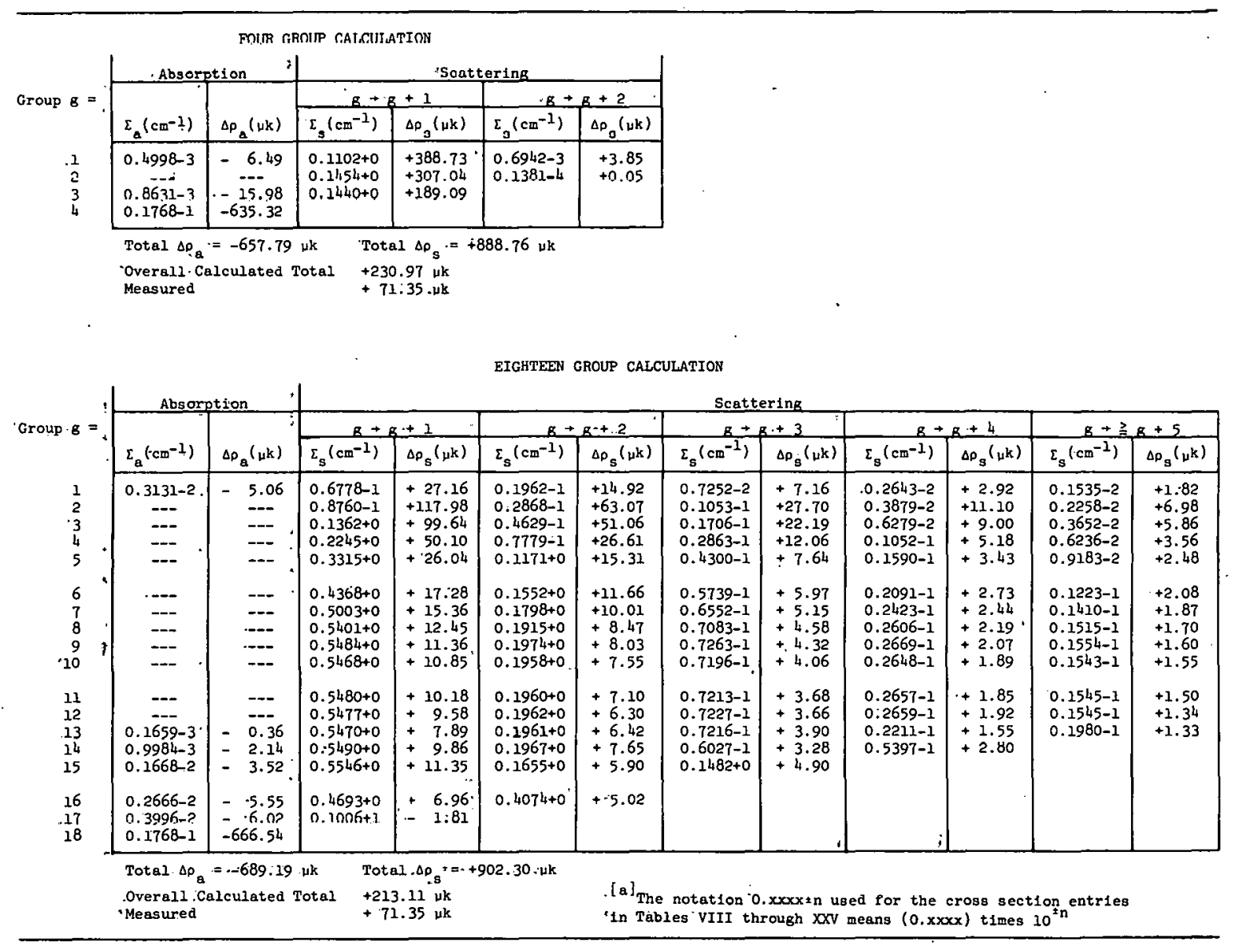




\section{TABLE XVIII}

GROUP CROSS SECTIONS ${ }^{[a]}$ AND REACTIVITIEES -- HEAVY W $\Lambda$ TER ARMF-II

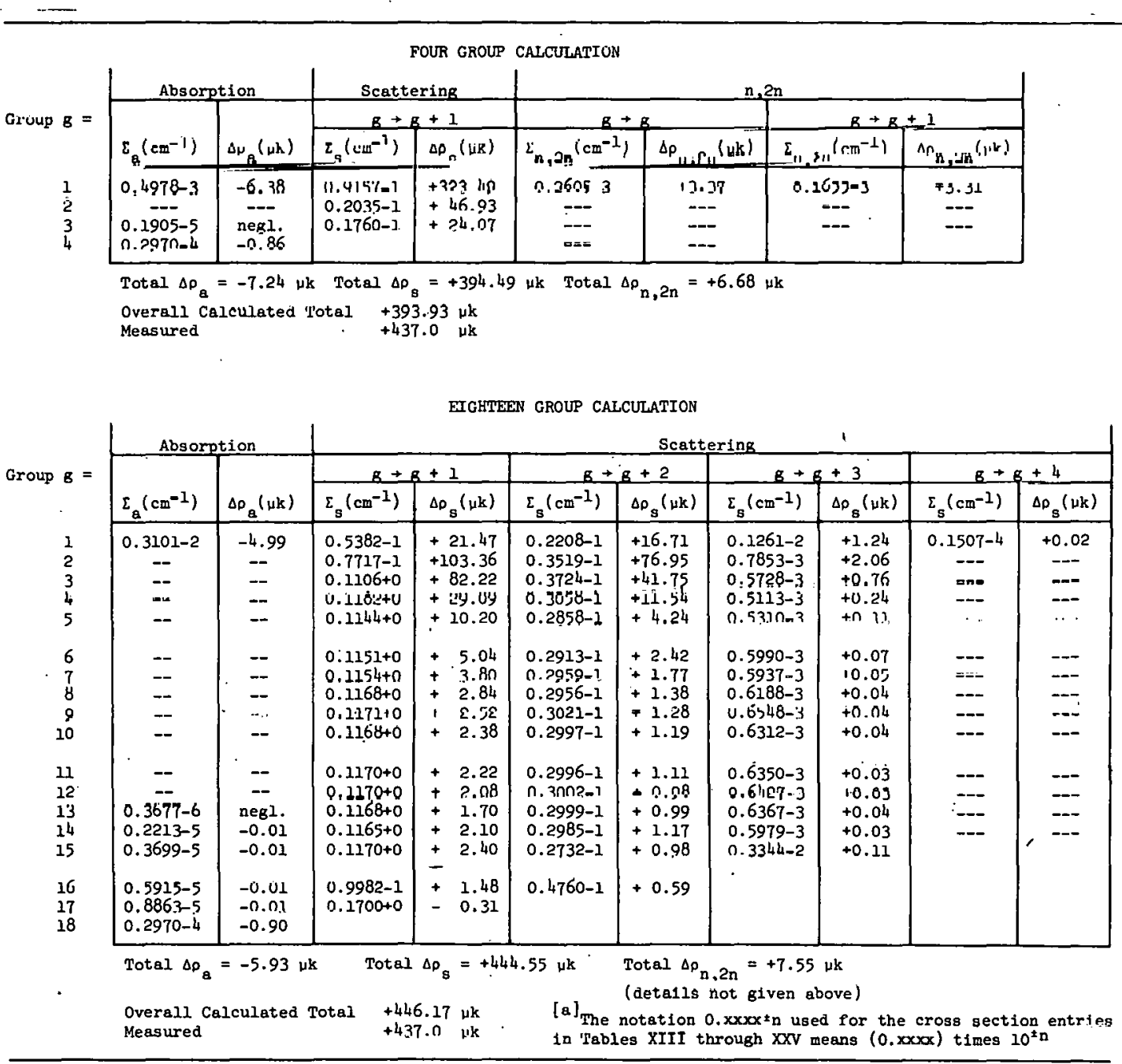


TABLE XIX

GROUP CROSS SECTIONS ${ }^{[a]}$ AND REACTIVITIES -- BERYLLIUM

ARMF-II

\begin{tabular}{|c|c|c|c|c|c|c|c|c|}
\hline \multirow{4}{*}{ Group $8=$} & \multicolumn{6}{|c|}{ FOURR GROUP CALCULATION } & & \\
\hline & \multicolumn{2}{|c|}{ Absorption } & \multirow{2}{*}{\multicolumn{2}{|c|}{$\frac{\text { Scatteri-g }}{8+g+1}$}} & \multicolumn{4}{|c|}{$n, 2 n$} \\
\hline & \multirow[b]{2}{*}{$\Sigma_{\varepsilon}\left(\mathrm{cm}^{-1}\right)$} & \multirow[b]{2}{*}{$\Delta \rho_{g}(\mu x)$} & & & \multicolumn{2}{|c|}{$g+g$} & \multicolumn{2}{|c|}{$8+g+1=$} \\
\hline & & & $\varepsilon_{\mathrm{s}}\left(\mathrm{cm}^{-1}\right)$ & $\Delta \rho_{s}(\mu \mathrm{k})$ & $\Sigma_{n, 2 n}\left(\mathrm{~cm}^{-1}\right)$ & $\Delta \rho_{n, 2 n}(: \mathrm{ik})$ & $\Sigma_{n, 2 n}\left(c^{-1}\right)$ & $\Delta \rho_{n, 2 n}(\mu k)$ \\
\hline \multirow[t]{2}{*}{$\begin{array}{l}1 \\
2 \\
3 \\
4\end{array}$} & $\begin{array}{c}0.5618-2 \\
--- \\
0.9800-3\end{array}$ & $\begin{array}{c}-76: 23 \\
--- \\
-28.62\end{array}$ & $\begin{array}{l}0.3841-1 \\
0.1620-1 \\
0.1415-1\end{array}$ & $\begin{array}{l}+141.58 \\
+37.12 \\
+19.55\end{array}$ & $\begin{array}{c}0.1363-1 \\
--- \\
---\end{array}$ & $\begin{array}{c}+184.94 \\
--- \\
---\end{array}$ & $\begin{array}{c}0: 5204-2 \\
=- \\
--\end{array}$ & $\begin{array}{c}+108.98 \\
--- \\
--\end{array}$ \\
\hline & $\begin{array}{l}\text { Total } \Delta p \\
\text { Overalil } \\
\text { Measured }\end{array}$ & $\begin{array}{l}-104 \\
\text { culate }\end{array}$ & & $\begin{array}{l}\hat{\rho}_{\mathrm{s}}= \\
24 \mathrm{\mu k} \\
4 \mu \mathrm{k}\end{array}$ & $: 25 \mu \mathrm{k}$ & a) $\Delta p_{n ; 2}$ & $293.92 \mu \mathrm{k}$ & \\
\hline
\end{tabular}

范

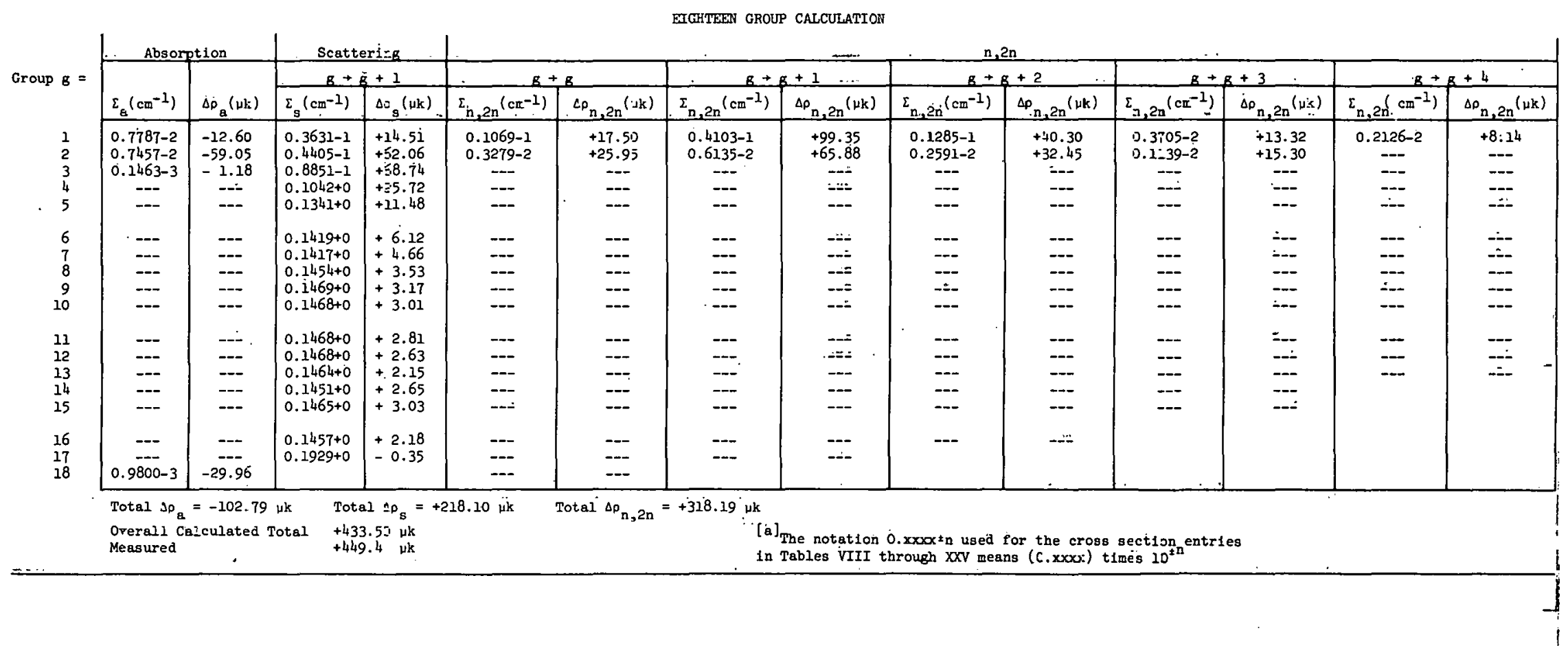


TABLE XX

GROUP CROSS SECTIONS ${ }^{[a]}$ AND REACTIVITIES -- CARBON

ARMF-II

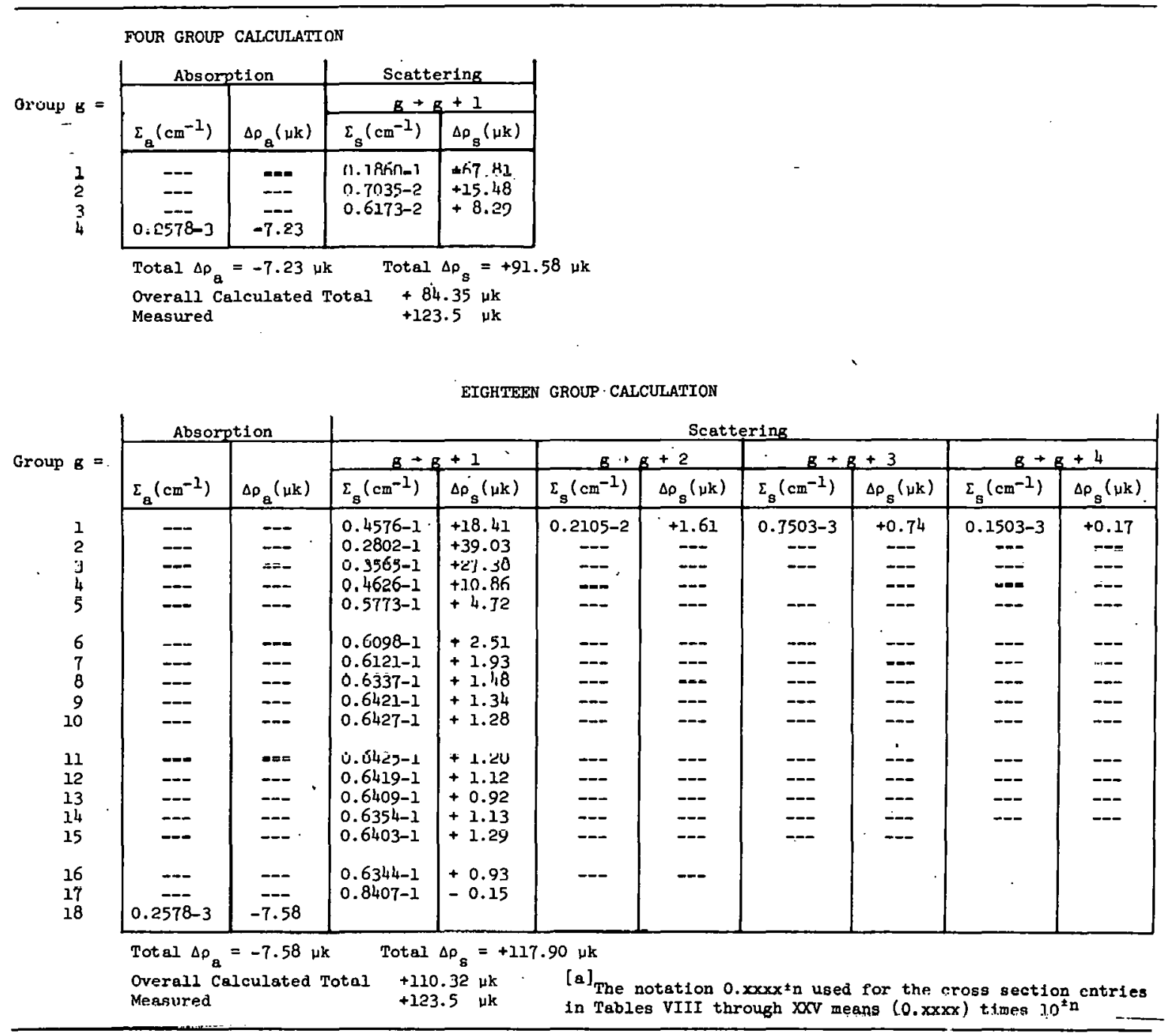




\section{TABLE XXI}

\section{GROUP CROSS SECTIONS ${ }^{[a]}$ AND REACTIVITIES --- MAGNESIUM ARMF-II}

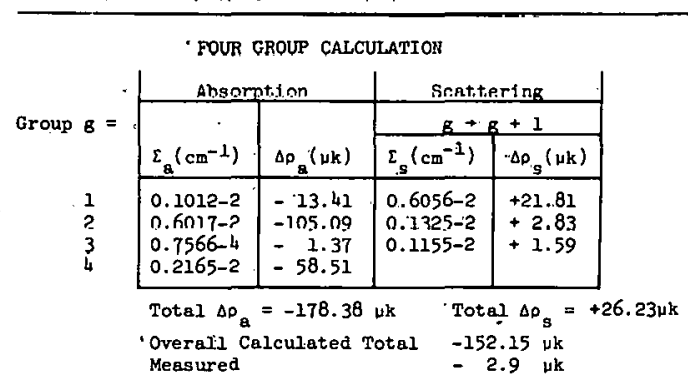

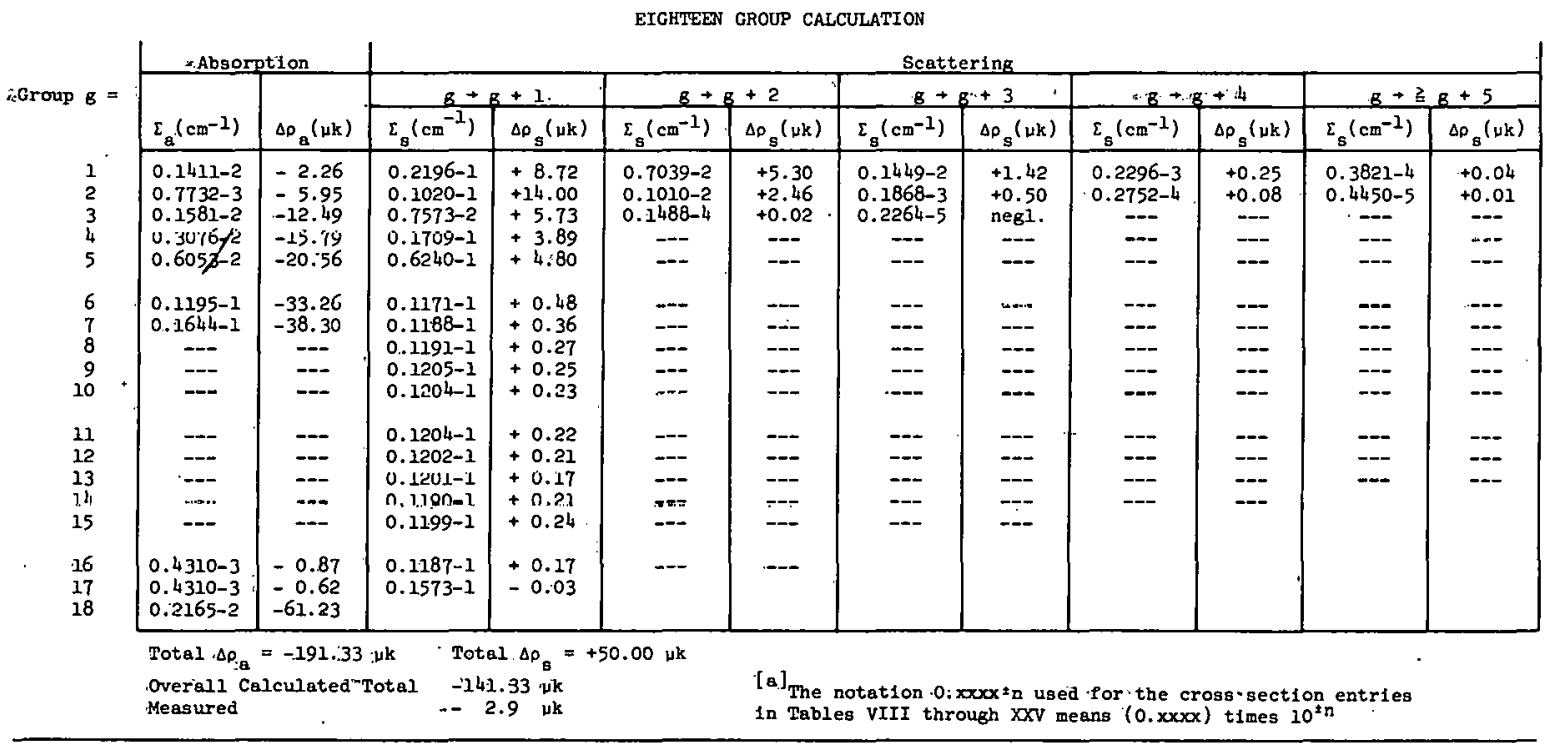


TABI.E XXTT

GROUP CROSS SECTIONS ${ }^{[a]}$ AND REACTIVITIES -- ALUMINUM ARMF-II

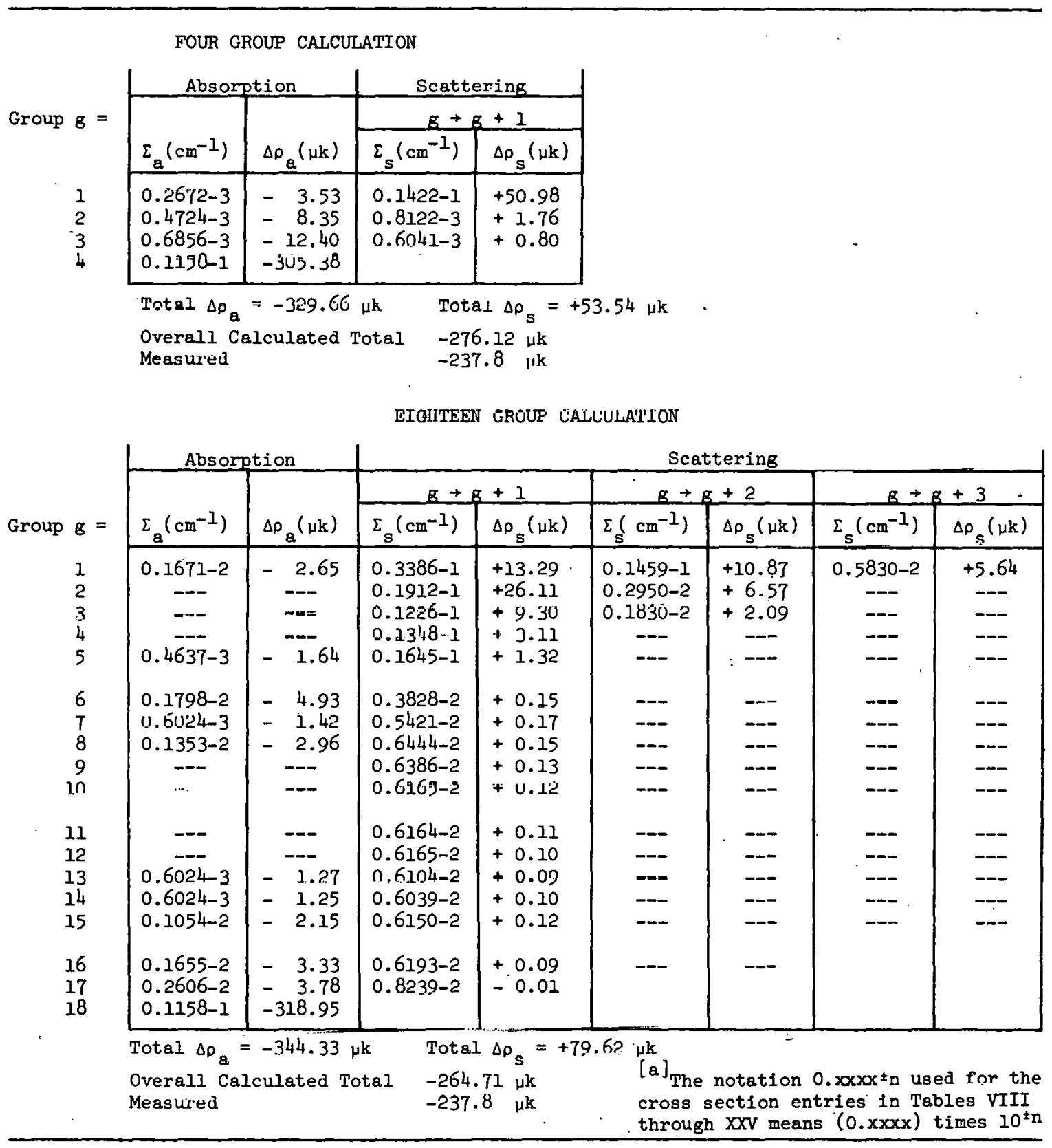


TABLE XXIII

GROUP CROSS SECTIONS ${ }^{[a]}$.AND REACTIVITIES -- ZIRCONIUM

ARMF-II

\begin{tabular}{|c|c|c|c|c|}
\hline \multirow{4}{*}{ Group $B=$} & \multicolumn{4}{|c|}{ FOUR GROUP CALCULATION } \\
\hline & \multicolumn{2}{|c|}{ Absorption } & \multirow{2}{*}{\multicolumn{2}{|c|}{$\frac{\text { Scatler } 1 \text { rug }}{8-8+1}$}} \\
\hline & \multirow[b]{2}{*}{$\Sigma_{a}\left(\mathrm{~cm}^{-1}\right)$} & \multirow[b]{2}{*}{$\Delta \rho_{\mathrm{a}}(\mu \mathrm{k})$} & & \\
\hline & & & $\varepsilon_{\mathrm{s}}\left(\mathrm{cm}^{-1}\right)$ & $\Delta \rho_{s}(\mu \mathrm{k})$ \\
\hline \multirow[t]{2}{*}{$\begin{array}{l}1 \\
2 \\
3 \\
4\end{array}$} & $\begin{array}{l}0.5496-4 \\
0.21 \% 11-2 \\
0.1092-1 \\
0.6341-2\end{array}$ & $\begin{array}{l}-0.74 \\
=34.30 \\
-200.03 \\
-173.03\end{array}$ & $\begin{array}{r}0.1450-1 \\
0.82 / 3-3 \\
.0 .5549-3\end{array}$ & $\begin{array}{r}+53.26 \\
+1.83 \\
+0.74\end{array}$ \\
\hline & $\begin{array}{l}\text { Total } \Delta p \\
\text { Overall } \\
\text { Measured }\end{array}$ & & $\begin{array}{l}\text { Tot } \\
-357 \\
-93\end{array}$ & $\begin{array}{l}\rho_{\mathrm{s}}= \\
\mathrm{\mu k \textrm {k }}\end{array}$ \\
\hline
\end{tabular}

EIGHTEEN GROUP CALCULATION

\begin{tabular}{|c|c|c|c|c|c|c|c|c|c|c|c|c|}
\hline \multirow{3}{*}{ - Group $\mathrm{g}=$} & \multicolumn{2}{|c|}{ Absorption } & \multicolumn{10}{|c|}{ Scattering } \\
\hline & \multirow[b]{2}{*}{$\varepsilon_{\mathrm{g}}\left(\mathrm{cm}^{-2}\right)$} & \multirow[b]{2}{*}{$\Delta 0_{\mathrm{a}}(\mu \mathrm{k})$} & \multicolumn{2}{|c|}{$B+B+1$} & \multicolumn{2}{|c|}{$g+B+2$} & \multicolumn{2}{|c|}{$B+8+3$} & \multicolumn{2}{|c|}{$B \rightarrow B+4$} & \multicolumn{2}{|c|}{$B \rightarrow B+5$} \\
\hline & & & $\varepsilon_{\mathrm{s}}\left(\mathrm{cm}^{-1}\right)$ & $\Delta \rho_{\mathrm{s}}(\mu \mathrm{k})$ & $\Sigma_{\mathrm{g}}\left(\mathrm{cm}^{-1}\right)$ & $\Delta \rho_{s}(u k)$ & $\Sigma_{\mathrm{g}}\left(\mathrm{cm}^{-1}\right)$ & $\Delta p_{8}(\mu k)$ & $\Sigma_{\mathrm{g}}\left(\mathrm{cm}^{-1}\right)$ & $\Delta \rho_{g}(\mu k)$ & $\Sigma_{\mathrm{s}}\left(\mathrm{cm}^{-1}\right)$ & $\Delta p_{s}(\mu k)$ \\
\hline $\begin{array}{l}1 \\
2 \\
3 \\
4 \\
.5\end{array}$ & $\begin{array}{c}-- \\
-- \\
0.3105-3 \\
-0.7463-3 \\
0.1485-2\end{array}$ & $\begin{array}{l}-- \\
-- \\
-2.54 \\
-3.99 \\
-5.37\end{array}$ & $\begin{array}{l}0.4530-1 \\
0.02689-1 \\
0.6874-2 \\
0.6198-2 \\
0.7132-2\end{array}$ & $\begin{array}{r}+18.15 \\
+37.45 \\
+5.39 \\
+1.47 \\
+0.58\end{array}$ & $\begin{array}{c}0.1158-1 \\
0.5369-2 \\
0.1551-3 \\
=- \\
--\end{array}$ & $\begin{array}{l}+8.80 \\
+12.21 \\
+0.18 \\
-- \\
--\end{array}$ & $\begin{array}{c}0.5014-2 \\
0.4413-3 \\
=- \\
=\end{array}$ & $\begin{array}{l}+4.95 \\
+1.20 \\
-- \\
--\end{array}$ & $\begin{array}{c}0.1082-2 \\
= \\
=- \\
=\end{array}$ & $\begin{array}{l}+1.19 \\
-- \\
-- \\
-\end{array}$ & $\begin{array}{c}0.3945-3 \\
=- \\
=- \\
=\end{array}$ & $\begin{array}{c}+0.46 \\
=- \\
=- \\
--\end{array}$ \\
\hline $\begin{array}{r}6 \\
7 \\
8 \\
.9 \\
10\end{array}$ & $\begin{array}{l}0.287 .3-2 \\
0.5658-2 \\
0.3136-1 \\
0.2256-1 \\
0.3601-1\end{array}$ & $\begin{array}{r}-7: 98 \\
-13.60 \\
.-25.28 \\
-48.95 \\
-77.23\end{array}$ & $\begin{array}{l}0.7844-2 \\
0.6924-2 \\
0.6554-2 \\
0.5627-2 \\
0.4272-2\end{array}$ & $\begin{array}{l}+0.32 \\
+0.22 \\
+0.14 \\
+0.12 \\
+0.08\end{array}$ & $\begin{array}{l}=- \\
\overline{-} \\
\overline{-}\end{array}$ & $\begin{array}{l}=- \\
=- \\
=-\end{array}$ & $\begin{array}{l}-- \\
\overline{-} \\
--\end{array}$ & $\begin{array}{l}= \\
= \\
= \\
--\end{array}$ & $\begin{array}{l}= \\
-- \\
=- \\
--\end{array}$ & $\begin{array}{l}\overline{-} \\
\overline{-} \\
\overline{--}\end{array}$ & $\begin{array}{l}-- \\
-- \\
-- \\
--\end{array}$ & $\begin{array}{l}=- \\
=- \\
-- \\
--\end{array}$ \\
\hline $\begin{array}{r}11 \\
412 \\
13 \\
14 \\
1.5\end{array}$ & $\begin{array}{c}0.2897-1 \\
\overline{-} \\
0.4298-3 \\
0.5366-3\end{array}$ & $\begin{array}{c}-61.89 \\
-= \\
-- \\
-0.91 \\
-1.12\end{array}$ & $\begin{array}{l}0.5781-2 \\
0.5781-2 \\
0.5766-2 \\
0.5704-2 \\
0.5768-2\end{array}$ & $\begin{array}{l}+0.11 \\
+0.10 \\
+0.08 \\
+0.10 \\
+0.12\end{array}$ & $\begin{array}{l}- \\
\overline{-} \\
\overline{-} \\
-\end{array}$ & $\begin{array}{l}-- \\
-- \\
-- \\
--\end{array}$ & $\begin{array}{l}-- \\
-- \\
-- \\
-\end{array}$ & $\begin{array}{l}=- \\
=- \\
=- \\
--\end{array}$ & $\begin{array}{l}=- \\
=-\end{array}$ & $\begin{array}{l}=- \\
=- \\
=\end{array}$ & $=$ & $\begin{array}{l}= \\
--\end{array}$ \\
\hline $\begin{array}{r}16 \\
-17 \\
.18\end{array}$ & $\begin{array}{r}0.9657-3 \\
0.1430-2 \\
\times 0.6341-2\end{array}$ & $\begin{array}{r}-1.98 \\
-2.22 \\
-181.01\end{array}$ & $\begin{array}{r}0.5728-2 \\
0.7568-2\end{array}$ & $\begin{array}{l}+0.08 \\
-0.01\end{array}$ & -- & -- & & ? & 8 & & & \\
\hline & $\begin{array}{l}\text { Total } \Delta p \\
\text { Overall: } \\
\text { - Messured }\end{array}$ & & $\begin{array}{r}106 \\
-34 \\
-9\end{array}$ & , & & & & & ans & $t$ & 1 & \\
\hline
\end{tabular}


TABLE XXIV

\section{GROUP CROSS SECTIONS ${ }^{[a]}$ AND REACTIVITIES -- LEAD \\ ARMF-II}

\begin{tabular}{|c|c|c|c|c|}
\hline \multirow{4}{*}{ Group $g=$} & \multicolumn{4}{|c|}{ FOUR GROUP CALCULATION } \\
\hline & \multicolumn{2}{|c|}{ Absorption ' } & \multicolumn{2}{|c|}{ Scattering } \\
\hline & & & & $1+1$ \\
\hline & $\Sigma_{\mathrm{g}}\left(\mathrm{cm}^{-1}\right)$ & $\Delta \theta_{\mathrm{g}}(\mathrm{uk})$ & $\Sigma_{\mathrm{s}}\left(\mathrm{cm}^{-1}\right)$ & $\Delta \rho_{\mathrm{s}}(\mu \mathrm{k})$ \\
\hline \multirow[t]{2}{*}{$\frac{1}{2}$} & $\begin{array}{c}\overline{-} \\
0 . \overline{2344-3} \\
0.4464-2\end{array}$ & $\begin{array}{c}-1 \\
-\overline{4} .20 \\
-118.99\end{array}$ & $\begin{array}{l}0.1069-1 \\
0.7869=3 \\
0.3397-3\end{array}$ & $\begin{array}{r}+38.11 \\
+\quad n .83 \\
+0.44\end{array}$ \\
\hline & $\begin{array}{l}\text { Total } \Delta p \\
\text { Oversil } \\
\text { Measured }\end{array}$ & & $\begin{array}{l}\text { Tota } \\
-83 . \\
-59 .\end{array}$ & \\
\hline
\end{tabular}

EIGHTEEN GROUP CALCULATION

\begin{tabular}{|c|c|c|c|c|c|c|c|c|c|c|c|c|}
\hline \multirow{3}{*}{ Group $8=$} & \multicolumn{2}{|c|}{ Absorption } & \multicolumn{10}{|c|}{ Scattering } \\
\hline & \multirow[b]{2}{*}{$\varepsilon_{\mathrm{a}}\left(\mathrm{cm}^{-1}\right)$} & \multirow[b]{2}{*}{$\Delta \Delta_{g}(\mu k)$} & \multicolumn{2}{|c|}{$8+8+1$} & \multicolumn{2}{|c|}{$8-8+2$} & \multicolumn{2}{|c|}{$8+8+3$} & \multicolumn{2}{|c|}{$8+8+4$} & \multicolumn{2}{|c|}{$B+B+5$} \\
\hline & & & $\varepsilon_{\mathrm{g}}\left(\mathrm{cm}^{-1}\right)$ & $\Delta p_{\mathrm{g}}(\mu \mathrm{k})$ & $\Sigma_{\mathrm{s}}\left(\mathrm{cm}^{-1}\right)$ & $\Delta 0_{\mathrm{g}}(\mu \mathrm{k})$ & $\Sigma_{\mathrm{g}}\left(\mathrm{cm}^{-1}\right)$ & $\Delta \rho_{g}(u k)$ & $\Sigma_{\mathrm{s}}\left(\mathrm{cm}^{-1}\right)$ & $\Delta \rho_{g}(\mu k)$ & $\varepsilon_{\mathrm{g}}\left(\mathrm{cm}^{-1}\right)$ & $\Delta \rho_{g}^{\cdot}(\mu k)$ \\
\hline $\begin{array}{l}1 \\
2 \\
3 \\
4 \\
5\end{array}$ & $\begin{array}{l}\bar{z} \\
\bar{z}\end{array}$ & $\begin{array}{l}= \\
=- \\
=\end{array}$ & $\begin{array}{l}0.2692-1 \\
0.1245-1 \\
0.2621-2 \\
0.2027-2 \\
0.28 K 3-?\end{array}$ & $\begin{array}{r}+10.38 \\
+16.88 \\
+1.98 \\
+0.46 \\
+0.23\end{array}$ & $\begin{array}{c}0.3244-1 \\
0.2555-2 \\
=- \\
=\end{array}$ & $\begin{array}{r}+23.74 \\
+5.65 \\
\overline{-} \\
=\end{array}$ & $\begin{array}{c}0.1135-1 \\
0.6008-3 \\
\ldots \\
= \\
=\end{array}$ & $\begin{array}{c}+10.79 \\
+1.59 \\
-- \\
--\end{array}$ & $\begin{array}{c}0.2079-2 \\
0.6142-4 \\
=- \\
--\end{array}$ & $\begin{array}{c}+2.21 \\
+0.18 \\
-- \\
--\end{array}$ & $\begin{array}{c}0.3475-3 \\
=- \\
=- \\
=-\end{array}$ & $\begin{array}{c}+0.39 \\
= \\
= \\
=\end{array}$ \\
\hline $\begin{array}{r}6 \\
7 \\
8 \\
9 \\
10\end{array}$ & $\begin{array}{l}= \\
\overline{-} \\
=\end{array}$ & $\begin{array}{l}= \\
= \\
= \\
--\end{array}$ & $\begin{array}{l}0.3164-2 \\
0.325 .2-2 \\
0.3480-2 \\
0.3513 .2 \\
0.3542-2\end{array}$ & $\begin{array}{l}+0.12 \\
+0.10 \\
+0.08 \\
+0.07 \\
+0.07\end{array}$ & $\begin{array}{l}- \\
- \\
= \\
--\end{array}$ & $\begin{array}{l}-- \\
\cdots \\
=- \\
--\end{array}$ & $\begin{array}{l}= \\
=- \\
=- \\
--\end{array}$ & $\begin{array}{l}=- \\
=- \\
=- \\
--\end{array}$ & $\begin{array}{l}= \\
\overline{-} \\
=\end{array}$ & $\begin{array}{l}= \\
\bar{z} \\
\overline{-}\end{array}$ & $\begin{array}{l}-- \\
=- \\
-- \\
--\end{array}$ & $\begin{array}{l}= \\
=- \\
= \\
--\end{array}$ \\
\hline $\begin{array}{l}11 \\
12 \\
13 \\
14 \\
15\end{array}$ & $\begin{array}{c}\overline{-} \\
0-1.81 \\
0.3296-3 \\
0.4115-3\end{array}$ & 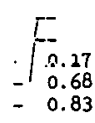 & $\begin{array}{l}0.3540-2 \\
0.3536-2 \\
0.35012 \\
0.3499-2 \\
0.3527-2\end{array}$ & $\begin{array}{l}+0.06 \\
+0.06 \\
0.09 \\
+0.06 \\
+0.07\end{array}$ & $\begin{array}{l}= \\
=- \\
=- \\
--\end{array}$ & $\begin{array}{l}=- \\
=- \\
=- \\
--\end{array}$ & $\begin{array}{l}-- \\
=- \\
=- \\
--\end{array}$ & $\begin{array}{l}-- \\
-- \\
-- \\
--\end{array}$ & $\begin{array}{l}-- \\
=- \\
--\end{array}$ & $\begin{array}{l}=- \\
\overline{--} \\
--\end{array}$ & $\begin{array}{l}-- \\
--\end{array}$ & $\begin{array}{l}\overline{-} \\
\overline{--}\end{array}$ \\
\hline \multirow[t]{2}{*}{$\begin{array}{l}16 \\
17 \\
18\end{array}$} & $\begin{array}{l}0.6593-3 \\
0.1096-2 \\
0.4468-2\end{array}$ & $\begin{array}{l}=1.31 \\
=\quad 1.58 \\
-124,27\end{array}$ & $\begin{array}{l}0.3492-2 \\
0.4626-2\end{array}$ & $\begin{array}{l}+0.05 \\
-0.01\end{array}$ & -- & -- & & & & & & . \\
\hline & $\begin{array}{l}\text { Total } \Delta p_{E} \\
\text { Overall } \\
\text { Mcasured }\end{array}$ & 128 & $\begin{array}{l}\text { Tot } \\
-53 \\
-59\end{array}$ & $\mu \mathrm{K}$ & & á T & III & $x v$ & the & 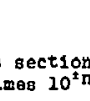 & & \\
\hline
\end{tabular}


TABLE XXV

GROUP CROSS SECTIONS ${ }^{[a]}$ AND REACTIVITIES -- BISMUTH A.RMF-II

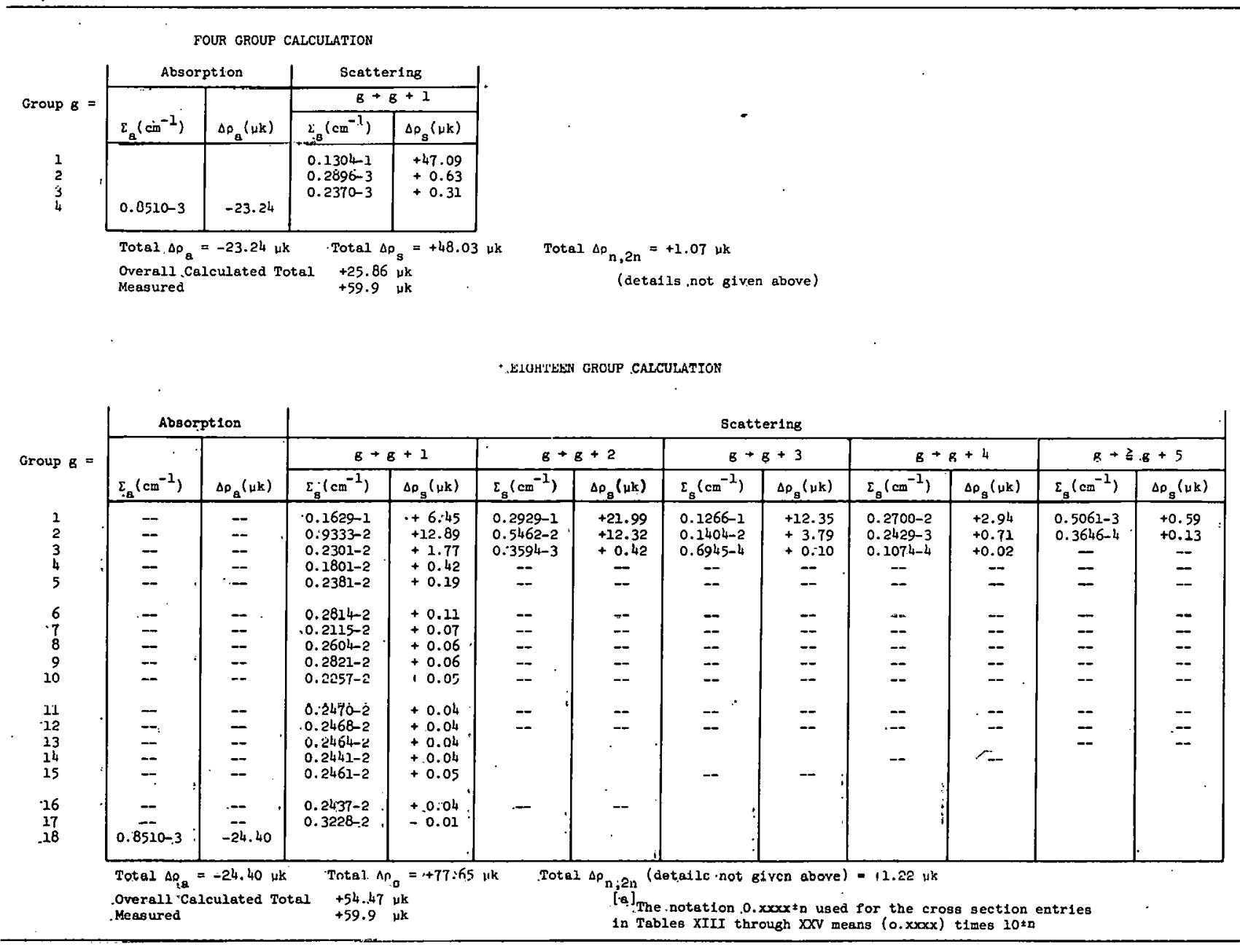




\section{REFERENCES}

1. E. E. Burdick, E. Fast, and D. W. Knight, The Advanced Reactivity Measurement Facilities, IDO-17005 (1964).

2. MTR-ETR Technical Branches Quarterly Report October 1-December 31 , 1960, IDO-16665 (1961) pp. 51-53.

3. E. Fast, Table of Reactivity Values for the RMF Calculated from the Inhour Equation, IDO-16361 (1956); K. V. Moore; Tables of Reactivity vs. Period for U-235; Pu-239; and U-233, IDO-16485 (Sept. 1958).

4. D. H. Gipson and R. A. Peereboom, DUZIT, ARMF Data Analysis Frogram for the IBM 7040, IDO-17026. (1964).

5. G. E. Putnam, Some Methods of Calculation of the Parameters in the Reactor Kinetics Equations, IDO-16983, February 1965.

6. W. G. Davey, "An Analysis of 23 ZPR-III Fast-Reactor Critical Experiments", Nucl. Sci. and Eng.', 19 (July 1964) pp. 259-273.

7. H. P. Flatt and D. C. Baller, The AIM-6 Code, NAA Internal Memorandum (1961) describing modifications of the AIM-5 code; see same authors' AIM-5 Multi-Group One-Dimensional Diffusion Equation Code, NAA-SR-4694, March 1960.

8. G. D. Joanou and J. S. Dudek, GAM-I: A Consistent $P_{1}$ Multigroup Code for the Calculations of Fast Neutron Spectra and Multigroup Constants, GA-1850, June 1961 .

9. R. H. Shudde and J. Dyer, TEMPEST-II, A Neutron Thermalization Code, TID-18284, June 1962.

10. J. W. Rogere, E. Fast, and D. $\Lambda$. Milleap, "Neutron Soattering Effects in Static Reactivity Measurements in the ARMF", Trans. Am. Nuc. Soc. 8, 258 (1965). Also see, Nuclear Technology Branches Quarterly Report, January 1 - March 31, 1965, ID0-17104, pp. 42-44.

11. H. P. Flatt, PERT, A Perturbation Theory Code, NAA Program Description from Nuclear Code Library, February 1.961.

12. Nuclear Technology Branches Quarteriy Report, October 1 - December 31 , 1964, ID0-17081, pp. 12-14. 